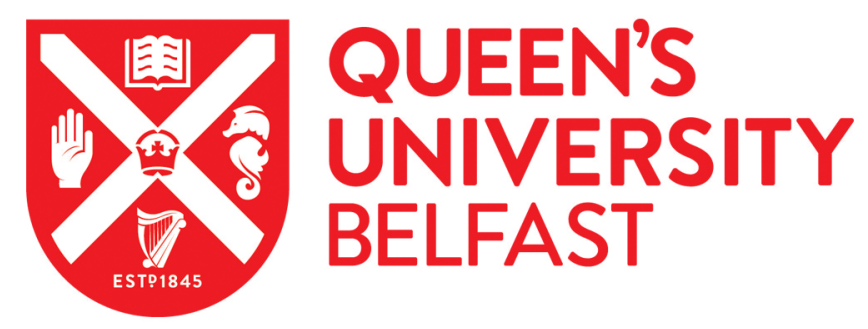

\title{
The effects of consumers and health providers working in partnership as an intervention for the promotion of personcentred health services
}

Lowe, D., Merner, B., Graham-Wisener, L., Walsh, L., \& Hill, S. (2019). The effects of consumers and health providers working in partnership as an intervention for the promotion of personcentred health services. Cochrane database of systematic reviews (Online), (7), [CD013373]. https://doi.org/10.1002/14651858.CD013373

Published in:

Cochrane database of systematic reviews (Online)

Document Version:

Publisher's PDF, also known as Version of record

Queen's University Belfast - Research Portal:

Link to publication record in Queen's University Belfast Research Portal

Publisher rights

Copyright 2019, The Cochrane Collaboration. Published by John Wiley \& Sons, Ltd.

This work is made available online in accordance with the publisher's policies. Please refer to any applicable terms of use of the publisher.

\section{General rights}

Copyright for the publications made accessible via the Queen's University Belfast Research Portal is retained by the author(s) and / or other copyright owners and it is a condition of accessing these publications that users recognise and abide by the legal requirements associated with these rights.

Take down policy

The Research Portal is Queen's institutional repository that provides access to Queen's research output. Every effort has been made to ensure that content in the Research Portal does not infringe any person's rights, or applicable UK laws. If you discover content in the Research Portal that you believe breaches copyright or violates any law, please contact openaccess@qub.ac.uk. 


\section{(E) Cochrane Library}

Cochrane Database of Systematic Reviews

\section{The effects of consumers and health providers working in partnership as an intervention for the promotion of person- centred health services (Protocol)}

Lowe D, Merner B, Graham-Wisener L, Walsh L, Hill S

Lowe D, Merner B, Graham-Wisener L, Walsh L, Hill S.

The effects of consumers and health providers working in partnership as an intervention for the promotion of person-centred health services. Cochrane Database of Systematic Reviews 2019, Issue 7. Art. No.: CD013373.

DOI: 10.1002/14651858.CD013373.

www.cochranelibrary.com

The effects of consumers and health providers working in partnership as an intervention for the promotion of person-centred health services (Protocol)

Copyright ๑ 2019 The Cochrane Collaboration. Published by John Wiley \& Sons, Ltd.

WILEY 


\section{TABLE OF CONTENTS}

HEADER . . . . . . . . . . . . . . . . . . . . . . . . . . . . . . . . . . . . . . . 1

ABSTRACT . . . . . . . . . . . . . . . . . . . . . . . . . . . . . . . . . . . . . . 1

BACKGROUND . . . . . . . . . . . . . . . . . . . . . . . . . . . . . . 1

Figure 1. . . . . . . . . . . . . . . . . . . . . . . . . . . . . . . . . . . . . . 2

Figure 2. . . . . . . . . . . . . . . . . . . . . . . . . . . . . . . . . . . . . .

Figure 3. . . . . . . . . . . . . . . . . . . . . . . . . . . . . . . . . . . . . . 5

Figure 4. . . . . . . . . . . . . . . . . . . . . . . . . . . . . . . . . . . . . . 6

OBJECTIVES . . . . . . . . . . . . . . . . . . . . . . . . . . . . . . . . . . . . . . . . . . . .

METHODS . . . . . . . . . . . . . . . . . . . . . . . . . . . . . . . . . . . . . . 7

ACKNOWLEDGEMENTS . . . . . . . . . . . . . . . . . . . . . . . . . . . . . . . . . . . . . .

REFERENCES . . . . . . . . . . . . . . . . . . . . . . . . . . . . . . . . . . . . . 15

ADDITIONAL TABLES . . . . . . . . . . . . . . . . . . . . . . . . . . . . . . . . . . . . . . . . . . . 19

APPENDICES . . . . . . . . . . . . . . . . . . . . . . . . . . . . . . . . . . . . . 26

CONTRIBUTIONS OF AUTHORS . . . . . . . . . . . . . . . . . . . . . . . . . . . . . . . . . . . . . . . . . . .

DECLARATIONS OF INTEREST . . . . . . . . . . . . . . . . . . . . . . . . . . . . . . . . . . . . . . . . . . . .

SOURCES OF SUPPORT . . . . . . . . . . . . . . . . . . . . . . . . . . . . . . . . . . . . . . . . . . .

NOTES . . . . . . . . . . . . . . . . . . . . . . . . . . . . . . . . . . . 29

The effects of consumers and health providers working in partnership as an intervention for the promotion of person-centred health services (Protocol)

Copyright $\odot 2019$ The Cochrane Collaboration. Published by John Wiley \& Sons, Ltd. 
[Intervention Protocol]

\title{
The effects of consumers and health providers working in partnership as an intervention for the promotion of person- centred health services
}

\author{
Dianne Lowe ${ }^{1}$, Bronwen Merner ${ }^{1}$, Lisa Graham-Wisener ${ }^{2}$, Louisa Walsh ${ }^{1}$, Sophie Hill ${ }^{1}$ \\ ${ }^{1}$ Centre for Health Communication and Participation, School of Psychology and Public Health, La Trobe University, Bundoora, \\ Australia. ${ }^{2}$ School of Psychology, Queen's University Belfast, Belfast, UK \\ Contact address: Dianne Lowe, Centre for Health Communication and Participation, School of Psychology and Public Health, La \\ Trobe University, Bundoora, VIC, 3086, Australia. d.lowe@latrobe.edu.au. \\ Editorial group: Cochrane Consumers and Communication Group. \\ Publication status and date: New, published in Issue 7, 2019.
}

Citation: Lowe D, Merner B, Graham-Wisener L, Walsh L, Hill S. The effects of consumers and health providers working in partnership as an intervention for the promotion of person-centred health services. Cochrane Database of Systematic Reviews 2019, Issue 7. Art. No.: CD013373. DOI: 10.1002/14651858.CD013373.

Copyright (C) 2019 The Cochrane Collaboration. Published by John Wiley \& Sons, Ltd.

\section{A B S T R A C T}

This is a protocol for a Cochrane Review (Intervention). The objectives are as follows:

To assess the effects of consumers and health providers working in partnership, as an intervention to promote person-centred health services.

\section{B A C K G R O U N D}

This review will assess the effects of consumers and health providers working in partnership, as an intervention to promote personcentred health services. In this review, we define 'working in partnership' as consumers and health providers making decisions together, in formal group formats (such as committees, councils, boards, or steering groups), about aspects of health service planning, delivery, or evaluation (or a combination), with the aim of making health services person-centred (see Glossary of key terms in Appendix 1). This review is being conducted concurrently with a Cochrane Qualitative Evidence Synthesis (QES) entitled Consumers and health providers working in partnership for the promotion of person-centred health services: a co-produced qualitative evidence synthesis (Merner 2019; Figure 1).

The effects of consumers and health providers working in partnership as an intervention for the promotion of person-centred health services (Protocol)

Copyright $\odot 2019$ The Cochrane Collaboration. Published by John Wiley \& Sons, Ltd. 
Figure I. Modified infographic comparing the Intervention effects review process (on the left) and the Qualitative evidence synthesis review process (on the right (Kaufman 20I I))

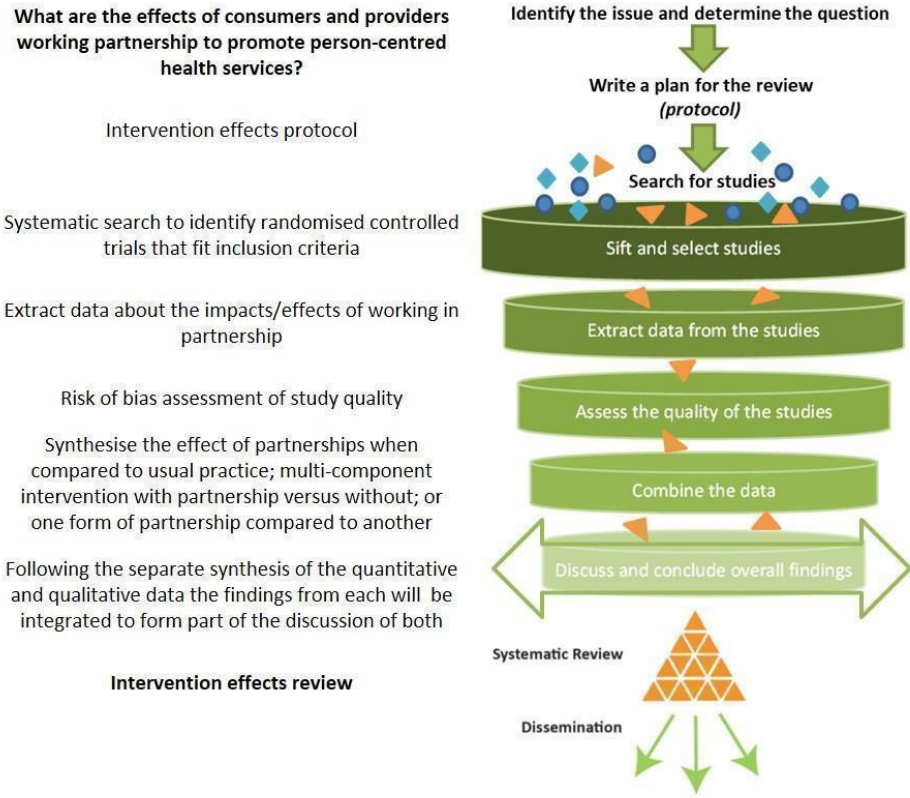

\author{
What are the barriers, facilitators \& experiences of \\ consumers and providers working in partnership to \\ promote person-centred health services? \\ Qualitative evidence synthesis protocol \\ Systematic search to identify qualitative studies and \\ purposively sample from identified studies \\ Extract data about barriers, facilitators \& experiences \\ of working in partnership from sampled studies \\ CERQual assessment of study quality \\ Synthesise the initial codes, develop descriptive \\ themes and then combine analytical themes \\ Following the separate synthesis of the quantitative \\ and qualitative data the findings from each will be \\ integrated to form part of the discussion of both \\ Qualitative evidence synthesis
}

\section{Description of the condition}

\section{Historical and theoretical context of working in partnership for the promotion of person-centred care}

Consumers and providers working in partnerships in healthcare decision-making, is based on paradigms of recovery, empowerment, and human, democratic, or consumer rights. The mental health consumer recovery and empowerment movement explicitly utilises consumer experiential knowledge through working in partnership, to transform and innovate services and policies (Pelletier 2011). In some countries, the impetus for working in partnership in decision-making at the health service level, in addition to the point of care level (consultation or encounter), has been driven by healthcare safety and quality standards and rights. For example, the Australian National Safety and Quality Health Service Standards mandate that health service organisations partner with consumers in health governance, policy, and planning to design, deliver, and evaluate healthcare systems and services (ACSQHC 2017). The Australian Charter of Healthcare Rights states that people using the Australian healthcare system have the right to participate in decision-making and choices about their own care, and about health service planning and policies (ACSQHC 2008).

\section{Person-centred care definition and features}

Worldwide, healthcare sectors are adopting person-centred principles to enhance quality of care, and empower consumers to participate in their care (Delaney 2018; Mockford 2012; Stone 2008; Tritter 2003). There are various definitions of person-centred care, and terms, such as individualised or personalised, and patient, family-, or user-centred care are conceptually similar (Greene 2012). Common to these terms and definitions is the provision of health care that emphasises personhood and partnership (Hubbard 2007). This review adopts the following definition of person-centred care: 'planning, delivery, and evaluation of health care that is grounded in mutually beneficial partnerships among healthcare providers, patients, and families' (IPFCC 2012).

Person-centred care is an overarching concept or ethos, which has often been implemented at the health service level. Its implementation may also affect interactions at the point of care in many different ways. For instance, the Picker Institute identifies the following principles for person-centred care, which underpin interventions at point of care: respecting consumer preferences and values; providing emotional support, physical comfort, information, communication, and education; continuity and transitions, coordination of, and access to care; and involvement of the family and friends (Picker Institute 1987). Person-centred care contrasts with doctor-centred care, which is criticised for being paternalistic, medically dominated, and illness oriented (Bardes 2012; Berwick 2009). 


\section{Working in partnership for the promotion of person- centred health services}

Working in partnership may be a key intervention for the promotion of person-centred health services. Working in partnership may impact organisational leadership, strategic vision, consumer involvement, measurement and feedback of consumer experience, staff capacity building, incentives, accountability, and a culture supportive of learning and change (Luxford 2011). Qualitative research has identified that factors embedded within the broader health service(s) and health system, and policies are important to facilitate person-centred care in the consultation process (i.e. at the point of care delivery (Batalden 2016; Leyshon 2015; Ogden 2017)).

At point of care, person-centred consultations typically have three main features: eliciting and skilfully listening to the consumer's personal narrative; encouraging the consumer's active partici- pation in goal setting; and documenting goals (Moore 2017). Interventions that support one or more of these features include shared decision-making (Legaré 2014), decision aids (Stacey 2017), personalised care planning (Coulter 2011), family-centred care (Shields 2012), or family-initiated care escalation interventions (Mackintosh 2017). These interventions promote personcentred care by focusing on consumer involvement in the clinical consultation process, which influences the responsiveness of care delivery at the level of individual consumers. Interpersonal and communication skills training of providers also helps to promote person-centred care in the consultation process (Dwamena 2012; Repper 2007).

In contrast, the current review will focus on the involvement of consumers in partnership with health providers as one of the key ways in which person-centred care can be promoted at the health service level i.e. upstream, at a higher level than the point of care (Figure 2).

Figure 2. Decision-making at different levels of the health system influences the person-centeredness of health services.

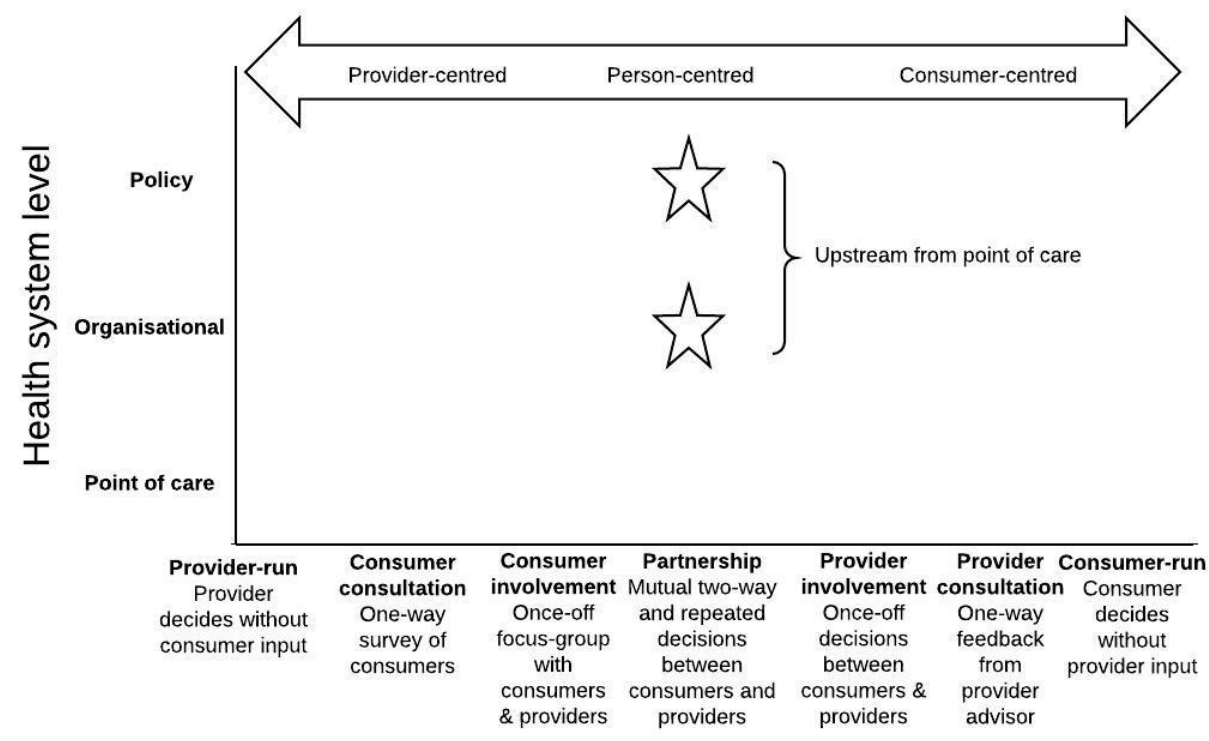

Decision process

The effects of consumers and health providers working in partnership as an intervention for the promotion of person-centred health 


\section{Description of the intervention}

\section{Defining working in partnership as an intervention}

The Australian Commission for Safety and Quality in Health Care defines partnerships as "healthcare organisations, healthcare providers, and policy makers actively working with people who use the healthcare system, to ensure that health information and services meet people's needs" (ACSQHC 2018). The World Health Organization (WHO) further defines partnership "as a collaborative relationship between two or more parties, based on trust, equality, and mutual understanding, for the achievement of a specified goal. Partnerships involve risks as well as benefits, making shared accountability critical" (WHO 2009). The WHO definition identifies partnerships as a form of collaboration. While 'collaborate' features on the participation spectrum (Arnstein 1969), and partnerships are considered an emergent process (Wildridge 2004; Wolf 2017), working in partnership is a distinct type of collaboration that occurs over a sustained time span to allow for the ongoing process of developing constructive relationships (Ocloo 2017). Hence, one-off consumer participation in collaborations, even when they are intended to promote person-centred care at the health service level, do not fit within the parameters of this review (Armstrong 2018; Fucile 2017; McKenzie 2017).

We will include trials that evaluate the effects of working in part- nership (i.e. collaborative relationships between at least one consumer and health provider, meeting jointly and regularly in formal group formats, to equally contribute to and collaborate in real-time), on decisions intended to promote person-centred care in one or more areas of a health service or services. These formal group formats could include committees, councils, boards, or steering groups, which meet more than once (either for an ongoing or time-limited duration) in real-time (face-to-face or virtually).

\section{Purpose(s) of working in partnership}

Promoting person-centred care at the health service level may be achieved by working in partnership to set priorities, identify problems, design solutions, or implement initiatives that reorient the responsiveness of health services towards the information and service delivery needs and experiences of consumers (Figure 3). Partnership approaches to develop policies or identify and monitor performance indicators may also influence person-centred care at the health service level. Working in partnership on such decisions may improve health service performance ratings of affordability, physical accessibility, acceptability, safety, quality, service availability, and accountability. Working in partnership may improve the responsiveness of health services to the consumers who use them ACSQHC 2011; Doyle 2013; Rathert 2012). Working in partnership on these decisional activities may result in changes that promote person-centred health services. 
Figure 3. How working in partnership may influence person-centred care outcomes at the health service level

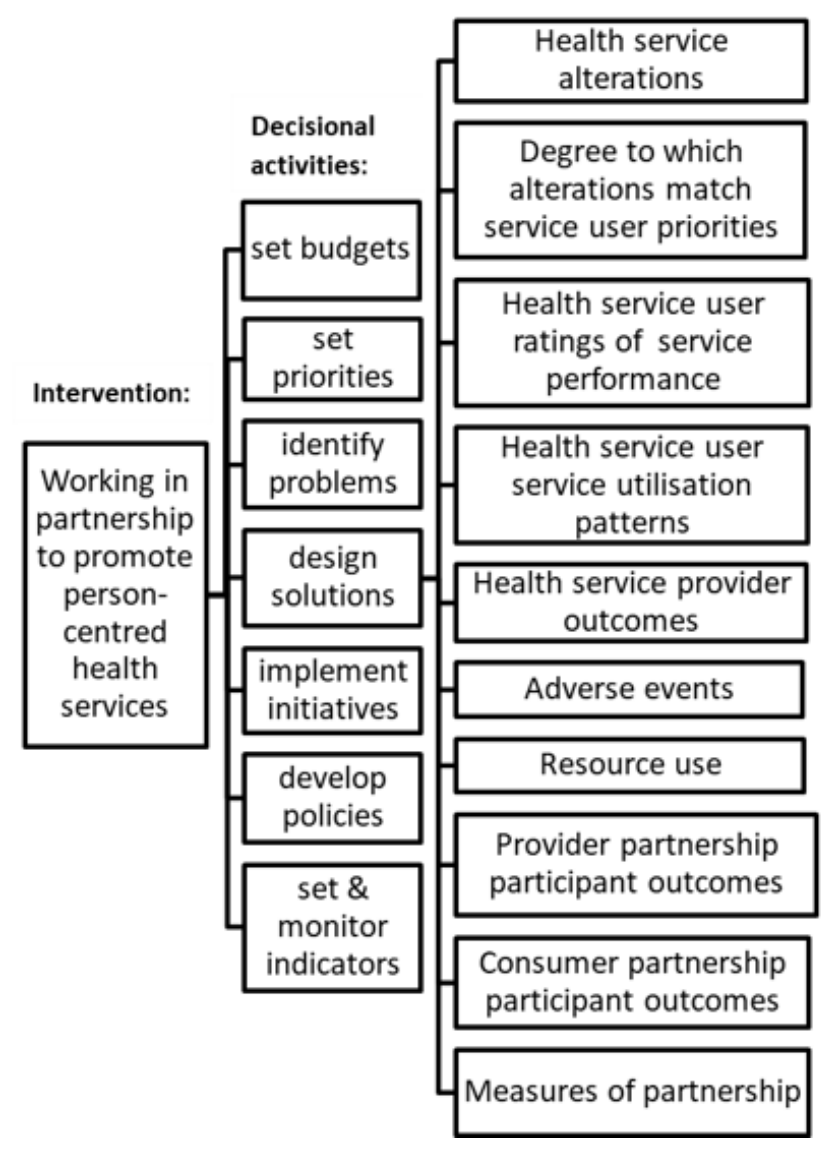

In research, numerous terms connote working in partnership at the health service level. Working in partnership underpins participatory action research, co-production, user-centred design, experience-based design, and co-design (Batalden 2016; Cooke 2016; Jun 2018; Sanders 2008). Common to these collaborative decision-making approaches, is that they empower consumers at the health service level, and promote the shift from 'user as subject' to 'user as partner' (Sanders 2008). Partnership approaches to decision-making may reorient health services from a 'provider-focus' to a 'patient-focus' (Luxford 2011), and are frequently illustrated by the maxim 'nothing about me, without me' (Berwick 2009; Coulter 2011; Delbanco 2001; Nelson 1998).

\section{Optimising partnership working}

Ottmann and colleagues caution that engagement and participation of consumers alone, does not suffice to enable this shift. They argue that to ensure truly collaborative decision-making, the contribution of stakeholder voices requires monitoring and amplifi- cation where necessary, in order to account for intrinsic power imbalances (Ottmann 2011). For example, in their research, administrative and operational 'imperatives' dominated consumers' voices; to address this power imbalance, the researchers adopted the role of consumer advocate (Ottmann 2011). We will conduct a subgroup analysis that focuses on the effects of attempts to address intrinsic power imbalances in preparation for partnerships, for example, by providing a salary or financial reimbursement, orientation, training, coaching, or support (via an advocate, facilitator, moderator, or mentor).

How consumers are selected can also contribute to power imbalances, for example, by handpicking or inviting 'appropriate' or 'acquiescent' representatives, or by overlooking class or ethnic groups from whom comments are seldom heard (Ocloo 2016). Therefore, in subgroup analysis, we will consider the methods of recruitment, and whether the researchers ensured the inclusion of a diverse consumer or provider participant group (e.g. care-givers, vulnerable people, range of health providers). Another power imbalance to be

The effects of consumers and health providers working in partnership as an intervention for the promotion of person-centred health 
considered is whether the partnership is professionally dominated (Ocloo 2016). We will conduct a subgroup analysis based on the ratio of consumers to providers (e.g. consumer majority, provider majority, or equal).

\section{How the intervention might work}

Working in partnership interventions might work by strengthening the demand responsiveness and local accountability of health services, by including consumers in health service planning and policy decision-making (Björkman Nyqvist 2017). Responsiveness and accountability require information about (1) the needs, preferences, experiences, and priorities of consumers of the service, as well as (2) ratings of health service(s), such as performance indicators. Consumers and health providers working in partnership, means that both consumer and provider perspectives are available, and feed into health service decision-making.

Recent trials focusing on working in partnership vary in the frame of reference for partnership decision-making. In some trials, the consumers and health providers directly involved in the partnership (the partnership participants) approach decision-making using their own experience as a point of reference (Björkman Nyquist 2017; Ong 2017; Palmer 2015; Palmer 2016). In other trials, the partnership participants are explicitly required to incorporate additional information that has been gathered systematically, as part of the trial, into their decision-making (Björkman 2009; Greco 2006; Gullo 2017; Waiswa 2016). This additional information may include the broader health service user perspectives (demand side), the broader provider perspectives (supply side), or health performance information (see Figure 4).

Figure 4. 'Working in partnership' interventions alone and as a component of multi-component interventions

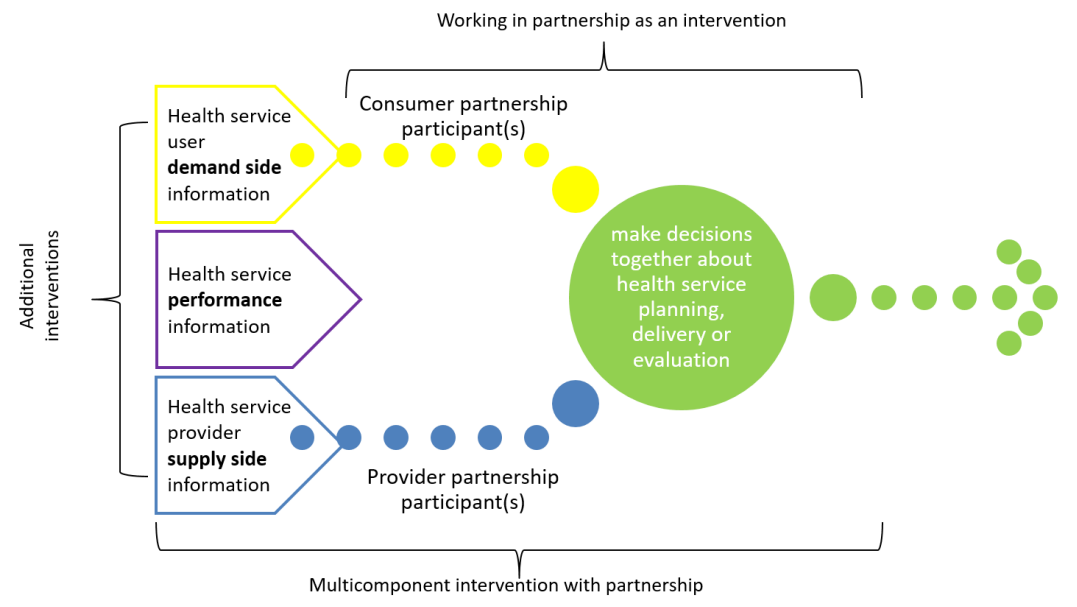

We will differentiate between working in partnership as an intervention on its own, which only incorporates the viewpoints of the consumer and provider partnership participants into their decision-making; and working in partnership as part of a multi-component intervention, in which partnership participants consider additional information (e.g. demand side, supply side, or performance information) that has been gathered systematically, as part of the trial, into their decision-making.

\section{Why it is important to do this review}

The dominant rationale for conducting this effectiveness review

is that it will parallel a co-produced Cochrane QES as identified above (Merner 2019). The Cochane QES will synthesise research on the views and experiences of consumers and health providers, and identify best practice principles for working in partnership. Together, this review and the QES will aim to form a comprehensive and cohesive assessment of the evidence on partnering. Trials evaluating the effects of upstream interventions of consumer involvement in developing health care policy, research, and services have been synthesised in other systematic reviews (Hubbard 2007; Nilsen 2006). A systematic review of the theory, barriers and en-

The effects of consumers and health providers working in partnership as an intervention for the promotion of person-centred health 
ablers for consumer and public involvement across health, social care and consumer safety is also planned (Ocloo 2017). However, no reviews have specifically evaluated the effects of consumers working in partnership, as an intervention to promote personcentred care at the health service level, which is the focus here. An earlier review in this area explored the effects of involving consumers in the planning and development of health care, but at that time, there were no comparative or experimental studies available (Crawford 2002). Crawford and colleagues identified that involving consumers contributed to changes to services. However, they also noted that the effects of involvement on quality of care (accessibility and acceptability of services) or impact on consumers' satisfaction, health, or quality of life, had not been examined (Crawford 2002). In the absence of trial evaluations, reviews based on research in this upstream context have focused on consumer participation and involvement predominantly as an agenda or aspiration, with guidance based on case studies of one-off collaboration examples. Sharma and colleagues identified that engaging people in partnerships, shared decision-making, and meaningful participation in health system improvement, all promoted person-centred care (Sharma 2015).

We are aware of recently conducted or planned trials in the area, and so a systematic review is timely (Björkman 2009; Björkman Nyqvist 2017; Boivin 2014; Greco 2006; Hanson 2014; Ong 2017; Palmer 2015; Palmer 2016; Waiswa 2016). The Cochrane Consumers and Communication Group has also identified the promotion and implementation of person-centred care as a priority review topic (Synnot 2018; Synnot 2019).

We are aware of a planned update for a Cochrane Review evaluating consumer engagement in research, policy, and healthcare services, which is being updated by Wiles and colleagues (Nilsen 2006; Wiles 2018). Unlike the forthcoming Wiles review, which focuses on all forms of consumer engagement (i.e. consult, involve, collaborate and empower), we will limit our focus to partnership approaches (i.e. collaborate - but with an ongoing or time-limited duration, excluding one-off collaborations). We will also limit our focus to decisional activities intended to promote person-centred care in one or more areas of a health service(s), whereas, Wiles 2018 will focus on broader types of activities in all areas of research, policy, and healthcare services (including public health and health promotion).

By focusing on partnership activities, our review will contribute to Cochrane's growing evidence base for interventions to promote person-centred care, which currently has an exclusive focus on consumer participation in interventions occurring at the point of care (Coulter 2015; Dwamena 2012; Legaré 2014; Mackintosh 2017; Repper 2007; Shields 2012; Stacey 2017).

\section{O B JEC T IVES}

To assess the effects of consumers and health providers working in partnership, as an intervention to promote person-centred health services.

\section{METHODS}

\section{Criteria for considering studies for this review}

\section{Types of studies}

We will include randomised controlled trials (RCTs), clusterRCTs, and quasi-RCTs (a trial in which randomisation is attempted, but subject to potential manipulation, such as allocating participants by day of the week, date of birth, or sequence of entry into trial), as we anticipate that few, properly conducted RCTs will have focused on consumers and health providers working in partnership.

\section{Types of participants}

We will include trials in which the following groups are participants.

1. Consumer partnership participants. Consumer partnership participants refers to people who are fulfilling an advisory or representative role within the partnership. These roles might include a consumer or patient representative; consumer consultant; consumer with acute or chronic condition(s), their caregiver or family member; community members, general public or citizens; representatives, consultants, or members of consumer organisations.

2. Health provider partnership participants. Health provider partnership participants refers to people who are fulfilling an advisory or representative role within the partnership. These roles might include, for example: a clinician (such as doctor, nurse, allied health, or community health worker from any discipline), health service manager, supervisor or administrator (including quality coordinators, chief executives, etc.), health policy maker, or consumer liaison officer. As we are interested in partnerships between consumers and health providers, we will exclude partnerships in which health providers take on the role of consumer, or partnerships between consumers and providers who are primarily health researchers or academics.

3. Health service users and health service providers. Health service users and health service providers refers to the consumers and providers who are not directly involved in the partnership intervention, but are participants in trials that evaluate the effects of the partnership intervention.

The Wiles review will exclude multi-stakeholder partnerships comprised of fewer than $50 \%$ consumers where the comparator is no intervention (Wiles 2018). In this review, provided the aim of the partnership is to promote person-centred care at the health

The effects of consumers and health providers working in partnership as an intervention for the promotion of person-centred health 
service level, we will include multi-stakeholder partnerships that include at least one consumer.

As long as the goal is to make decisions to promote person-centred care; partnership groups may be multi-stakeholder. As long as they include at least one consumer; partnerships may be committees that develop in-service training or vocational education curriculum directed towards post-registration or post-graduate level students.

\section{Types of interventions}

We will include trials evaluating the effects of consumers and health providers working in partnership as an intervention, to make decisions with the aim of promoting person-centred care in one or more areas of a health service or services. We will include trials of working in partnership in formal groups that meet faceto-face or virtually, more than once.

We define person-centred care as "planning, delivery, and evaluation of health care that is grounded in mutually beneficial partnerships among healthcare providers, patients, and families" (IPFCC 2012). Examples of person-centred care decisions at the health service level include: identify appropriate and responsive healthcare indicators; improve continuity or follow-up of care; service (re)development, (re)design of physical spaces, or improve coordination of care across providers and settings (or a combination). We will include trials evaluating the effects of consumers and providers working in partnership in formal groups or committees to develop in-service training or vocational education curriculum directed towards post-registration or post-graduate level students (i.e. student cohort likely to be existing providers, and therefore partnership intervention may influence person-centeredness of health service).

We define health services as public or privately funded services that provide direct care to consumers in primary (e.g. community health centres, general practitioner practices, private practices, dispensaries), secondary (e.g. specialist outpatient clinics), or tertiary settings (e.g. hospitals). We will include home and residential services only when they primarily provide health or nursing care (e.g. home-based nursing services, nursing homes, residential rehabilitation services, or hospices).

Working in partnership has three key components (see Table 1): (1) both consumer and provider participants meet (2) jointly in a formal group format over time, to (3) to consider or make an actual decision that relates to the person-centeredness of health service(s).

We will assess three comparisons in this review. Comparisons 1 and 2 will assess the effects of partnership versus no partnership (with no other differences between groups), while comparison 3 will compare the effects of different versions of partnership.

Comparison 1. Consumers and health providers working in partnership compared to usual practice without partnership (i.e. usual ways of decision-making may contain some but not all key components of working in partnership).

Studies for this comparison answer the question: 'compared to usual practice without partnership, what is the effectiveness of consumers and health providers working in partnership, as an intervention?'. For example, 'what is the effect of facilitated partnership (intervention) compared to no partnership (usual practice)?' illustrates this comparison (Palmer 2015).

Examples of usual practice may include:

- decision-making involves some consumer input, but decisions are not made jointly;

- providers independently make decisions;

- decision-making meets some key components, but group format is informal, meets once-off, or does not meet together in real-time.

Comparison 2. Consumers and health providers working in partnership, as part of a multi-component intervention, compared to the same multi-component intervention without consumers and health providers working in partnership.

Studies for this comparison answer the question: 'what is the effectiveness of a multi-component intervention that includes consumers and health providers working in partnership, compared to the same multi-component intervention without partnership? '. For example, 'what is the effect of facilitated partnership plus health service consumer (demand side) information (multi-component intervention with partnership) compared to health service consumer (demand side) information without partnership (same multi-component intervention without partnership)?' illustrates this comparison (Greco 2006).

For example, a multi-component intervention may include cointerventions, such as health service consumer or provider information (demand and supply), or health service performance information (or both). Working in partnership would be part of one multi-component intervention arm, but not the other.

Comparison 3. One form of consumers and health providers working in partnership, compared to another form of consumers and health providers working in partnership.

Studies for this comparison answer the question: 'what is the effectiveness of one form of consumers and health providers working in partnership intervention compared with another form of consumers and health providers working in partnership intervention?'. For example, both groups have working in partnership interventions that fulfil all key components, but the intervention and comparator groups differ in the nature of a key feature, such as partnership participant composition (ratio of consumers and providers), or frequency (ongoing versus time limited), or format (online format versus face-to-face) of the meetings. We are yet to identify a study as an example of this comparison.

The effects of consumers and health providers working in partnership as an intervention for the promotion of person-centred health 


\section{Excluded interventions}

We will exclude trials where the comparison does not enable us to isolate the effects of consumers and providers working in partnership. This may include:

- Consumers and health providers working in partnership as part of a multi-component intervention compared to usual practice, or

- Consumers and health providers working in partnership, compared to an active control that does not include working in partnership (i.e. comparator is a different intervention).

In these cases, the comparisons will not allow us to evaluate the effect of working in partnership as an intervention, as the intervention and comparator groups differ on more than just the partnership component. An example illustrative of an excluded comparison is, 'what is the effect of health service consumer (demand side) information plus partnership (multi-component intervention with partnership) compared to no health service consumer (demand side) information and no partnership (usual practice)? (Boivin 2014).

As working in partnership is a distinct type of collaboration that occurs over time, we will exclude one-off collaborations involving consumers in group formats, even when they are intended to promote person-centred care. We will exclude studies that involve partnering with consumers for decision-making about an individual's care or treatment. We will also exclude studies about partnering with consumers for health services research (planning, undertaking, or disseminating research), including a health service's management of research (research funding panels, setting research priorities, research ethics and research governance (Gray-Burrows 2018)).

We will exclude trials that examine committees that develop educational programmes or training for pre-registration or undergraduate students, as we are interested in working in partnership as a strategy to promote person-centred health services and undergraduate students may not yet be employed as providers, and therefore less able to either directly or indirectly influence the person-centeredness of the health service as part of the intervention (Klein 1999).

As we are interested in consumer-provider partnerships, we will exclude studies of researchers or academics working in partnership with consumers if providers are not also partnership participants. Similarly, we will exclude studies in which researchers or academics are working in partnership with health providers, if consumers are not partnership participants.

There may be some trials that are included in this review and another Cochrane Review in progress, Interventions for improving medical students' interpersonal communication in medical consultations (Gilligan 2016).

\section{Types of outcome measures}

This is the first Cochrane review on this topic and so we will aim to include a wide range of outcomes to inform future conceptual development and research. It is also possible that we may identify some outcomes that we did not anticipate at the protocol stage, but which we feel should be included in the review because they are important to consumers or health providers making a decision. If this occurs, we will provide justification and the difference will be reported in the 'Differences between protocol and review' section.

\section{Primary outcomes}

Health service alterations (changes to services resulting from decisions)

- Addition, rationalisation, substitution, expansion, or revision of health services (e.g. changes to policies, performance indicators, resources, processes or systems, programmes, settings (e.g. relocating a stroke rehabilitation service from the hospital to the community), education, information, physical structures, or culture or values of services)

\section{Degree to which health service alterations reflect health service user (trial participant) priorities (demand responsiveness)}

- Comparability of partnership decision(s) with health service end user preference(s) or priorities

\section{Health service user (trial participant) health service performance ratings (local accountability)}

- Physical accessibility, e.g. simplified appointment procedures, extended opening times, transport to unit, parking, signage, security

- Affordability

- Acceptability e.g. satisfaction, retention or disengagement of existing consumers, attracting new consumers, appointment attendance or nonattendance

- Safety

- Quality

- Accountability

Health service user (trial participant) ratings of health service utilisation patterns

- Uptake of altered services or changes in coverage

\section{Health service provider (trial participant) outcomes}

- Satisfaction, staff engagement, retention or turnover, wellbeing

The effects of consumers and health providers working in partnership as an intervention for the promotion of person-centred health 


\section{Adverse events}

- Measures of complaints, harms, litigation, damage to health service reputation, staff disengagement or turnover, increased rate of consumer failure to attend appointments, etc.

\section{Secondary outcomes}

\section{Resource use}

- Cost (time, money) associated with decision-making process (e.g. cost of organising and running meetings, training (providers and consumers), remuneration, coordination, or meeting space)

- Cost (time, money) associated with implementing new or changes in service

\section{Consumer (partnership participant) outcomes*}

- Attendance and retention rates in formal group formats

- Preparedness to participate (e.g. feeling informed, motivation or empowerment to be involved, attitudes towards partnership, etc.)

- Experiences of participation (e.g. satisfaction, preferences, knowledge, well-being, involvement, etc.);

- Adverse outcomes and experiences (e.g. isolation, exploitation, uncertainty, conflict, decreased well-being, disengagement from health service)

\section{Provider (partnership participant) outcomes*}

- Attendance and retention rates in formal group formats

- Preparedness to participate (e.g. feeling informed, confidence, attitudes towards partnership, etc.)

- Experiences of participation (e.g. satisfaction, preferences, job satisfaction, well-being, etc.)

- Adverse outcomes and experiences (e.g. dissatisfaction, worsening attitudes towards consumers, emotional exhaustion, work overload, decreased well-being, disengagement or resigning from employment, and conflict)

\section{Measures of partnership among provider and consumer partnership participants*}

- Degree of shared decision-making involvement, capacity building, trust, etc

*likely to be measured for both the intervention and control groups only in comparison 3 (e.g. in head-to-head comparison of partnership interventions).

We will not exclude studies based on the presence or absence of outcomes reported.
Where more than one outcome measure is available in one trial for the same outcome:

- We will select the primary outcome that has been identified by the study authors.

- Where no primary outcome was identified, select the one specified in the sample size calculation.

- If there are no sample size calculations, rank the effect estimates (i.e. list them in order from largest to smallest) and select the median effect estimate. Where there is an even number of outcomes, we will select the outcome whose effect estimate is ranked $n / 2$, where $n$ is the number of outcomes.

We will use the selection steps above to inform the statistical analysis (i.e. pooling, synthesis). However, it may be appropriate to collect data on more than one outcome measure per category per trial to inform descriptive and narrative findings. Where a study reports multiple outcome measures for the same outcome, we will extract all, and review authors will meet to discuss and identify the outcome measure most relevant to person-centred health care (whether objective or subjective).

Two review authors will independently assign the outcomes reported in each included study to the review's outcome categories, and resolve any differences in categorisation by involving a third review author.

\section{Timing of outcome assessment}

We will group time points into short-, medium-, and long-term time points. For the purpose of meta-analysis, we will select one time point for each outcome from each study. How the identified time points will be grouped will be decided at review stage.

\section{Main outcomes for 'Summary of findings' tables}

We will report the following outcomes in the 'Summary of findings' tables.

- Health service alterations (changes to services resulting from decisions)

- Degree to which changed service reflects consumer research participant priorities (demand responsiveness)

- Health service user (trial participant) ratings of health service performance (local accountability)

- Health service user (trial participant) health service utilisation patterns

- Resources associated with decision-making process

- Resources associated with implementing decisions (e.g. changed services)

- Adverse events

\section{Search methods for identification of studies}

The effects of consumers and health providers working in partnership as an intervention for the promotion of person-centred health 


\section{Electronic searches}

We will search the following electronic databases:

- The Cochrane Central Register of Controlled Trials

(CENTRAL, The Cochrane Library, latest issue);

- MEDLINE Ovid (2000 to present);

- Embase Ovid (2000 to present);

- PsycINFO Ovid (2000 to present); and

- CINAHL EBSCO (2000 to present).

We will search online trial registers (ClinicalTrials.gov), and the WHO International Clinical Trials Registry Platform ( ICTRP) for ongoing and recently completed studies.

We present the strategy for MEDLINE Ovid in Appendix 2. We will tailor these strategies to other databases and report them in the review.

The qualitative review scoping searches of this topic show a proliferation of studies about partnering with consumers published after 2000. The definition of person-centred care has developed considerably over the past decades to include aspects broader than partnering with individuals during consultations. Our assessment shows that a consistent and recognisable definition of working in partnership to promote person-centred health services has been used most often since 2000. We aim to assess and build the evidence on what is currently accepted as partnering in the context of person-centred health services. Therefore, in this review, we will search from 2000 onwards to exclude older, conceptually inconsistent studies. Due to resource constraints, we will exclude publications in languages other than English.

\section{Searching other resources}

We will search relevant grey literature sources, such as websites (e.g. the WHO, Health Quality Improvement Partnership UK, Involve UK, Health Foundation UK, Beryl Institute, James Lind Alliance, International Association for Public Participation, Institute for Patient- and Family- Centered Care (formerly Picker Institute Europe), Health Issues Centre Australia, Planetree, The King's Fund, Consumer Health Organisaiton of Canada, Candian Institutes of Health Research (CIHR), and the patient group, One Voice Patient \& Family Advisory Council, Mayo Clinic USA). We will contact experts in the field and authors of included studies for advice on other relevant studies. We will also search reference lists of included studies and relevant systematic reviews.

\section{Data collection and analysis}

\section{Selection of studies}

Two review authors will independently screen all titles and abstracts identified from searches to determine which meet the inclusion criteria. We will retrieve in full text any papers identified as potentially relevant by at least one review author. Two review authors will independently screen full-text articles for inclusion or exclusion, with discrepancies resolved by discussion, and by consulting a third review author, if necessary, to reach consensus. We will list all potentially relevant papers excluded from the review at this stage as excluded studies, with reasons provided in the 'Characteristics of excluded studies' table. We will also provide citation details and any available information about ongoing studies, and collate and report details of duplicate publications, so that each study (rather than each report) is the unit of interest in the review. We will report the screening and selection process in an adapted PRISMA flow chart (Liberati 2009).

\section{Data extraction and management}

Two review authors will independently extract data from included studies. Any discrepancies will be resolved by discussion until consensus is reached, or in necessary, through consultation with a third author. We will develop and pilot a data extraction form, using Cochrane Consumers and Communication's data extraction template. We will extract data on the following items: details of the study (aim of intervention, study design, description of intervention and comparison group; risk of bias items (random sequence generation, allocation sequence concealment, blinding of participants and personnel, blinding of outcome assessment, completeness of outcome data, selective outcome reporting, and other sources of bias; whether the study explicitly sought informed consent or obtained ethics approval); criteria related to precision of the study (e.g. use of a power calculation); reporting standards, or whether the validity or reliability (or both) of outcome measures was addressed; funding source and the declaration of interests for the primary investigators; details of consumers and providers (numbers, where and how recruited, training, purpose of partnership); setting (country, region, health department, organisation or service type); see Table 2. One review author will enter all extracted data into Review Manager 5; a second review author will independently check for accuracy against the data extraction sheets (Review Manager 2014).

\section{Assessment of risk of bias in included studies}

We will assess and report on the methodological risk of bias of included studies in accordance with the Cochrane Handbook for Systematic Reviews of Interventions, and the Cochrane Consumers and Communication guidelines, which recommend the explicit reporting of the following individual elements for RCTs: random sequence generation; allocation sequence concealment; blinding (participants, personnel); blinding (outcome assessment); completeness of outcome data, selective outcome reporting (Higgins 2011; Ryan 2013).

For cluster-RCTs, we will also assess and report the risk of bias associated with an additional domain, selective recruitment of cluster participants. 
We will assess and report quasi-RCTs as being at a high risk of bias for random sequence generation.

We will consider blinding separately for different outcomes, where appropriate (for example, blinding may have the potential to differently affect subjective versus objective outcome measures). We will judge each item as being at high, low, or unclear risk of bias as set out in the criteria provided by Higgins 2011, and provide a quote from the study report and a justification for our judgement for each item in the 'Risk of bias' table.

We will deem studies to be at the highest risk of bias if we score them as at high or unclear risk of bias for either the sequence generation or allocation concealment domains, based on growing empirical evidence that these factors are particularly important potential sources of bias (Higgins 2011).

In all cases, two review authors will independently assess the risk of bias of included studies, resolving any disagreements by discussion, to reach consensus. We will contact study authors for additional information about the included studies, or for clarification of the study methods, as required. We will incorporate the results of the 'Risk of bias' assessment into the review through standard tables, systematic narrative description, and commentary about each of the elements. We will provide an overall assessment of the risk of bias of included studies and a judgment about the internal validity of the review's results.

\section{Measures of treatment effect}

For dichotomous outcomes, we will analyse data based on the number of events and the number of people assessed in the intervention and comparison groups. We will use these to calculate the risk ratio (RR) and 95\% confidence interval (CI). For continuous measures, we will analyse data based on the mean, standard deviation (SD), and number of people assessed for both the intervention and comparison groups to calculate mean difference (MD) and $95 \% \mathrm{CI}$. If the MD is reported without individual group data, we will use this to report the study results. If more than one study measures the same outcome using different tools, we will calculate the standardised mean difference (SMD) and 95\% CI using the inverse variance method in Review Manager 5 (Review Manager 2014).

\section{Unit of analysis issues}

If we include cluster-RCTs, we will check for unit-of-analysis errors. If we find errors, and sufficient information is available, we will re-analyse the data using the appropriate unit of analysis, by taking account of the intracluster correlation (ICC). We will obtain estimates of the ICC by contacting authors of included studies, or impute them using estimates from external sources. If it is not possible to obtain sufficient information to re-analyse the data, we will report effect estimates and annotate unit-of-analysis error.

\section{Dealing with missing data}

We will attempt to contact study authors to obtain missing data (participant, outcome, or summary data). For participant data, we will, where possible, conduct analysis on an intention-to-treat basis; otherwise, data will be analysed as reported. We will report on the levels of loss to follow-up and reasons, and assess this as a source of potential bias.

For missing outcome or summary data, we will impute missing data where possible, and report any assumptions in the review. We will investigate, through sensitivity analyses, the effects of any imputed data on pooled effect estimates.

\section{Assessment of heterogeneity}

We will examine the heterogeneity across studies, as it is anticipated that there will be considerable differences in settings, interventions, participants, and outcomes, and use this descriptive analysis to determine the most appropriate groupings of studies within each of the review's main comparisons. Where studies are considered similar enough (based on consideration of these factors) to allow pooling of data using meta-analysis, we will assess the degree of heterogeneity by visual inspection of forest plots, and by examining the $\mathrm{Chi}^{2}$ test for heterogeneity. We will report our reasons for deciding that studies were similar enough to pool statistically. Heterogeneity will be quantified using the $\mathrm{I}^{2}$ statistic. An I ${ }^{2}$ value of $50 \%$ or more will be considered to represent substantial levels of heterogeneity, but this value will be interpreted in light of the size and direction of effects and the strength of the evidence for heterogeneity, based on the P value from the $\mathrm{Chi}^{2}$ test (Higgins 2011). Where heterogeneity is present in pooled effect estimates, we will explore possible reasons for variability by conducting subgroup analysis.

Where we detect substantial clinical, methodological, or statistical heterogeneity across included studies, we will not report pooled results from meta-analysis, but instead will use a narrative approach to data synthesis. In this event, we will clearly report our reasons for deciding that studies were too dissimilar to meta-analyse. We will also attempt to explore possible clinical or methodological reasons for this variation by grouping studies that have similar populations, intervention features, and methodological features to explore differences in intervention effects.

\section{Assessment of reporting biases}

We will assess reporting bias qualitatively, based on the characteristics of the included studies (e.g. if only small studies that indicate positive findings are identified for inclusion), and if information that we obtain from contacting experts and authors of studies suggests that there are relevant unpublished studies.

If we identify sufficient studies (at least 10) for inclusion in the review, we will construct a funnel plot to investigate small study effects, which may indicate the presence of publication bias. We

The effects of consumers and health providers working in partnership as an intervention for the promotion of person-centred health 
will formally test for funnel plot asymmetry, and choose the appropriate test based on advice in Higgins 2011. When interpreting the results, we will bear in mind that there may be several reasons for funnel plot asymmetry.

\section{Data synthesis}

We will decide whether to meta-analyse data based on whether the interventions in the included trials are similar enough in terms of participants, settings, intervention, comparison, and outcome measures to ensure meaningful conclusions from a statistically pooled result. Due to the anticipated variability in the populations and interventions of included studies, we will use a random-effects model for meta-analysis.

We will include data from all randomised trials in meta-analysis, regardless of their rating for sequence generation, but will conduct sensitivity analyses, excluding those at unclear or high risk of bias, to examine the robustness of the meta-analysis results to methodological limitations of the included studies.

The way in which studies are grouped for analysis will depend on the number of included studies and the types of comparisons identified. For example, it may make sense to group the included studies that examine comparison 1 into high intensity usual practice (i.e. where usual decision-making practice includes some (more than one) but not all key components of working in partnership) or low intensity usual practice (i.e. usual practice limited to just one key component of working in partnership).

If we are unable to pool the data statistically using meta-analysis, we will provide clear reasons for this decision, and will conduct a narrative synthesis of results. We will present the major outcomes and results, organised by intervention categories according to the major types or aims (or both) of the identified interventions. Depending on the assembled research, we may also explore the possibility of organising the data by population, and explore heterogeneity in the results by investigating the subgroups identified below. Within the data categories, we will explore the main comparisons of the review:

- Partnership intervention versus usual practice (without partnership).

- Multi-component intervention with partnership versus multi-component intervention without partnership.

- One form of partnership intervention versus another.

Where studies assess the effects of more than one intervention, we will compare each separately with usual practice, and with one another.

\section{Using the synthesised quantitative findings to supplement the Cochrane qualitative evidence synthesis (QES)}

We will use a sequential approach to integrate the findings of this effectiveness review with the findings of the concurrent QES
(Harden 2018). We will finalise the aims and method of integration of the findings after the syntheses of the QES and this review are both complete. Following the separate synthesis of the quantitative and qualitative data, we will integrate the findings from each review to form part of the discussion of both of them. For example, the effectiveness review may provide information on the effects of partnership interventions on health service, provider, or consumer outcomes. The findings of the QES could link with the effectiveness review by providing contextual information on partnership approaches, and may help to explain why partnering does (or does not) influence specific outcomes. We anticipate that the QES will highlight issues of commonality and differences between the perceptions of health providers and consumers about personcentred care that may help to interpret the results of the effectiveness review. The QES may also identify outcomes that should be measured in future trials.

We do not anticipate many included trials, and expect that there will be considerably more qualitative studies in the forthcoming QES (Merner 2019). It is possible that the discussion and integration of the findings of both reviews will need to focus more on future research questions, but we aim to use both reviews, where possible, to inform our understanding of the effectiveness of interventions, and the implementation of partnering approaches.

\section{Subgroup analysis and investigation of heterogeneity}

If statistical subgroup analysis is not possible, which is likely, we will use the possible explanatory factors outlined here to explore the effects of interventions narratively.

Subgroup analyses will examine trials that explicitly attempt to address intrinsic power imbalances in preparation for partnerships (e.g. provision of salary or financial reimbursement, orientation, training, coaching, or support (e.g. via an advocate, facilitator, moderator, mentor, or consumer liaison officer) versus trials that did not); the ratio of consumers to providers (consumer majority versus provider majority); and the partnership duration (e.g. ongoing versus time-limited).

\section{Sensitivity analysis}

We will explore the impact of assumptions, imputed data, and the inclusion of studies at high risk of bias by:

- Comparing the results of studies at higher and lower risk of bias (remove from the analysis studies with a high or unclear rating on the sequence generation item of the 'Risk of bias' tool and see how robust the results are when based only on studies with low risk of bias).

- Compare results based on imputed data, e.g. when ICC values have been taken from external sources for cluster-RCTs.

\section{'Summary of findings' table}


We will prepare a separate 'Summary of findings' table, using GRADEpro software, to present the results of the meta-analysis or narrative synthesis (or both) for each major comparisons of the review, for the seven key outcomes outlined in the Types of outcome measures section (GRADEpro GDT). We will provide a source and rationale for each assumed risk cited in the table(s). Two review authors will independently assess the quality of the evidence, using the criteria described in Schünemann 2011, study limitations, indirectness, imprecision, inconsistency, and reporting bias.

\section{Ensuring relevance to decisions in health care}

Both this protocol and the related QES protocol were co-designed with a Stakeholder Advisory Panel who will also be directly involved in the production of the QES at the review stage (Merner 2019). A draft of this current protocol was shared with the Stakeholder Advisory Panel prior to a stakeholder workshop day. During the workshop, the stakeholders provided the following feedback on the protocol.

- Refine definitions to reflect practice e.g. consumers and health providers often 'make decisions together' rather than 'sharing responsibility for decisions'.

- Define terms in understandable, or lay language.

- A diagram or infographic showing the differences between the effectiveness review and the QES is needed to help with clarity.

- Explain the differences between point of care versus partnership in health service.

- Clarify if Consumer Liaison Officer as a complaints role or advocate role.

- Consider (in subgroup analyses) role of power differentials, consumer representatives, whether led or chaired by consumer or professional, who initiated the group, who leads partnerships, and hierarchies within service (e.g. palliative care -

multidisciplinary care).

- Relevant outcomes might include: participatory outcomes, such as cohesion or collaboration (perhaps in measures of increasing involvement or capacity building); consumer participation as stepping stone to higher-level participation and involvement (i.e. capacity building, which benefits the individual consumer and the system); and personal well-being. Decisions might result in: changes in systems or services; improved accessibility (of parking, signage, security and reduced theft); more dissemination of changed services and outcomes; rationalised services (i.e. increased focus on those that consumers want, on those that add value); growth in services (i.e. may demonstrate increased need); change of setting (e.g. hospital service to community, hospital to home setting); staff engagement, retention, etc; and financial cost savings (i.e. if experienced staff stay on, this may be more cost-effective than adding new staff). Adverse events might include stakeholder disengagement, negative impacts on reputation, noncompliance, and failure to attend at point of care.

- Relevant grey literature search sites might include: Beryl Institute, Health Foundation UK; work with First Nations people has led the way with community-led engagement.

The Stakeholder Panel feedback resulted in the following changes to this protocol.

- Changed 'sharing responsibility for decisions' to 'make decisions together' or alternatively 'jointly make decisions'.

- Glossary added to define terms (see Appendix 1).

- Modified the infographic of the funnel diagram to outline the different steps in the qualitative and quantitative systematic review approaches (see Figure 1).

- Developed figure to highlight the level of the health system where partnership-based decision-making might impact the person-centeredness of health services (i.e. national, state, regional (policy) level, or local health service governance (organisational) level, as opposed to the direct care (point of care) level (see Figure 2)).

- Removed the term Consumer Liaison Officer as an example in the background, and referred instead to a consumer advocate role as a support component of facilitated partnerships.

- Added to the methods our intent to consider the identified potential sub-group analyses, if number of included trials allows.

- Added the identified outcomes.

- Added the grey literature resources.

In addition, we will discuss the findings from both reviews with the Stakeholder Panel. We will ask the panel to provide feedback on the integration of the results of the effectiveness review with the QES. We will also ask panel members for their input on the implications of the results. Panel members suggested relevant organisations for the dissemination stage, to ensure the protocol and review will reach consumer, health provider, research, and policy networks. A content expert will provide feedback on the protocol and review, as part of Cochrane Consumers and Communication's standard editorial process.

\section{ACKNOWLEDGEMENTS}

We thank the editors and staff of Cochrane Consumers and Communication, particularly our contact editor Dr. Rebecca Ryan for their input to this protocol, Anne Parkhill for developing the search strategy, and the external referees.

We gratefully acknowledge the input and guidance of the Stakeholder Advisory Panel formed for the QES (Merner 2019). The Australian-based Stakeholder Advisory Panel consists of consumers, healthcare professionals, and health policy makers. The members of the Panel are: Leslie Arnott (Consumer Representative, Victoria), Susan Biggar (Australian Health Practitioner Reg- 
ulation Agency (AHPRA), Victoria, and Consumer Representative, Victoria), Noni Bourke (Chief of Organisational Support \& Development, Bass Coast Health, Victoria), Paul Bryden (Consumer Representative, Queensland), Renee Chmielewski (Manager, Planning and Patient Experience, The Royal Victorian Eye and Ear Hospital, Victoria), Leia Earnshaw (Consumer Representative, Australian Capital Territory), Marie Gill (Consultant, Gill and Wilcox Consultancy, Victoria), Fiona Martin (Clinical Practice Lead/Health Psychologist, Catholic Care, Victoria), Nathalie Martinek (Practitioner Trauma \& Fatigue: Prevention \& Recovery Professional Mentor \& Mediator for Physicians and Other Health Professionals (until October 2018)), Louise McKinlay (Director, Patient Experience \& Partnerships, Safer Care Victoria), David Menzies (Manager, Chronic Disease Programs, South Eastern
Melbourne Primary Health Network, Victoria), Nancy Messino (Clinical Trials Quality Officer, Victorian Comprehensive Cancer Centre, Victoria), Anne Mussared (Consumer Representative, South Australia), Naomi Poole (Program Manager, Partnering with Consumers, Australian Commission on Safety and Quality in Health Care, New South Wales), Nora Refahi (Consumer Representative, Victoria), Lorraine Smith (School of Pharmacy, Faculty of Medicine and Health, University of Sydney, Camperdown, New South Wales), Roshni Sonawane (Consultant Paediatrician, Rockingham General Hospital and Wexford Specailist clinics, Murdoch, Western Australia), and Cheryl Wardrope (Patient Safety and Quality Service, Children's Health Queensland Hospital and Health Service, South Brisbane, Queensland).

\section{R E F E R E N C E S}

\section{Additional references}

\section{ACSQHC 2008}

Australian Commission on Safety and Quality in Health Care. Australian Charter of Healthcare Rights. www.safetyandquality.gov.au/national-priorities/charter-ofhealthcare-rights/ (accessed 24 July 2018).

\section{ACSQHC 2011}

Australian Commission on Safety and Quality in Health Care. Patient-centred care: improving quality and safety through partnerships with patients and consumers. www.safetyandquality.gov.au/our-work/partneringconsumers/person-centred-care (accessed 24 July 2018).

\section{ACSQHC 2017}

Australian Commission on Safety and Quality in Health Care. National Safety and Quality Health Service Standards. 2nd ed. www.safetyandquality.gov.au/publications-andresources/resource-library/national-safety-and-qualityhealth-service-standards-1 (accessed 2 July 2019).

\section{ACSQHC 2018}

Australian Commission on Safety and Quality in Health Care. Review of key attributes of highperforming person-centred healthcare organisations. www.safetyandquality.gov.au/our-work/partneringconsumers/person-centred-healthcare-organisations (accessed 2 July 2019).

\section{Armstrong 2018}

Armstrong MJ, Mullins CD, Gronseth GS, Gagliardi AR. Impact of patient involvement on clinical practice guideline development: a parallel group study. Implementation Science 2018;13(1):55. DOI: 10.1186/s13012-018-0745-6

\section{Arnstein 1969}

Arnstein SR. A ladder of citizen participation. Journal of the American Institute of Planners 1969;35:216-24. DOI: $10.1080 / 01944366908977225$
Bardes 2012

Bardes CL. Defining 'patient-centered medicine'. New England Journal of Medicine 2012;66(9):782-3. DOI: 10.1056/NEJMp1200070

Batalden 2016

Batalden M, Batalden P, Margolis P, Seid M, Armstrong G, Opipari-Arrigan L, et al. Coproduction of healthcare service. BMJ Quality \& Safety 2016;25(7):509-17. DOI: 10.1136/bmjqs-2015-004315

\section{Berwick 2009}

Berwick DM. What 'patient-centered' should mean: confessions of an extremist. Health Affairs 2009;28(4): w555-65. DOI: 10.1377/hlthaff.28.4.w555

\section{Björkman 2009}

Björkman M, Svensson J. Power to the people: evidence from a randomized field experiment on community-based monitoring in Uganda. Quarterly Journal of Economics 2009;124(2):735-69. [www.jstor.org/stable/40506242]

\section{Björkman Nyqvist 2017}

Björkman Nyqvist M, de Walque D, Svensson J. Experimental evidence on the long-run impact of community-based monitoring. American Economic Journal: Applied Economics 2017;9(1):33-69. DOI: 0.1257/ app. 20150027

Boivin 2014

Boivin A, Lehoux P, Lacombe R, Burgers J, Grol R. Involving patients in setting priorities for healthcare improvement: a cluster randomized trial. Implementation Science 2014;9:24. DOI: 10.1186/1748-5908-9-24

\section{Cooke 2016}

Cooke J, Langley J, Wolstenholme D, Hampshaw S. 'Seeing' the difference: the importance of visibility and action as a mark of 'authenticity' in co-production. Comment on 'Collaboration and co-production of knowledge in healthcare: opportunities and challenges'. International

The effects of consumers and health providers working in partnership as an intervention for the promotion of person-centred health 
Journal of Health Policy and Management 2016;6(6):345-8. DOI: $10.15171 /$ ijhpm.2016.136

\section{Coulter 2011}

Coulter A, Collins A. Making shared decision making a reality: no decision about me, without me. www.kingsfund.org.uk/publications/making-shareddecision-making-reality (accessed 24 July 2018).

\section{Coulter 2015}

Coulter A, Entwistle VA, Eccles A, Ryan S, Shepperd $S$, Perera R. Personalised care planning for adults with chronic or long-term health conditions. Cochrane Database of Systematic Reviews 2015, Issue 3. DOI: 10.1002/ 14651858.CD010523.pub2

\section{Crawford 2002}

Crawford MJ, Rutter D, Manley C, Weaver T, Bhui K, Fulop N, et al. Systematic review of involving patients in the planning and development of health care. BMJ 325; 7375:1263. DOI: 10.1136/bmj.325.7375.1263

\section{Delaney 2018}

Delaney LJ. Patient-centred care as an approach to improving health care in Australia. Collegian 2018;25(1): 119-23. DOI: 10.1016/j.colegn.2017.02.005

\section{Delbanco 2001}

Delbanco T, Berwick DM, Boufford JI, Edgman-Levitan $S$, Ollenschläger G, Plamping D, et al. Healthcare in a land called People Power: nothing about me without me. Health Expectations 2001;4(3):144-50. DOI: 10.1046/ j.1369-6513.2001.00145.x

Doyle 2013

Doyle C, Lennox L, Bell D. A systematic review of evidence on the links between patient experience and clinical safety and effectiveness. BMJ Open 2013;3(1):e001570.

Dwamena 2012

Dwamena F, Holmes-Rovner M, Gaulden CM, Jorgenson S, Sadigh G, Sikorskii A, et al. Interventions for providers to promote a patient-centred approach in clinical consultations. Cochrane Database of Systematic Reviews 2012, Issue 12. DOI: 10.1002/14651858.CD003267.pub2

Flemming 2019

Flemming K, Booth A, Garside R, Tunçalp Ö, Noyes J. Qualitative evidence synthesis for complex interventions and guideline development: clarification of the purpose, designs and relevant methods. BMJ Global Health 2019;4: e000882.

\section{Fucile 2017}

Fucile B, Bridge E, Duliban C, Law MP. Experience-based co-design: a method for patient and family engagement in system-level quality improvement. Patient Experience Journal 2017;4(2):53-60.

Gilligan 2016

Gilligan C, James EL, Snow P, Outram S, Ward BM, Powell $\mathrm{M}$, et al. Interventions for improving medical students' interpersonal communication in medical consultations. Cochrane Database of Systematic Reviews 2016, Issue 11. DOI: 10.1002/14651858.CD012418

\section{GRADEpro GDT [Computer program]}

McMaster University (developed by Evidence Prime). GRADEpro GDT. Version accessed prior to 19 November 2018. Hamilton (ON): McMaster University (developed by Evidence Prime), 2015.

Gray-Burrows 2018

Gray-Burrows KA, Willis TA, Foy R, Rathfelder M, Bland $\mathrm{P}$, Chin A, et al. Role of patient and public involvement in implementation research: a consensus study. $B M J$ Quality \& Safety 2018;27(10):858-64. [doi:10.1136/ bmjqs-2017-006954]

Greco 2006

Greco M, Carter M, Powell R, Sweeny K, Jolliffe J, Stead $\mathrm{J}$. Impact of patient involvement in general practice. Education for Primary Care 2006;17:486-96.

\section{Greene 2012}

Greene SM, Tuzzio L, Cherkin D. A framework for making patient-centered care front and center. Permanente Journal 2012;16(3):49-53. [PUBMED: 23012599]

Gullo 2017

Gullo S, Galavotti C, Sebert Kuhlmann A, Msiska T, Hastings P, Marti CN. Effects of a social accountability approach, CARE's Community Score Card, on reproductive health-related outcomes in Malawi: a cluster-randomized controlled evaluation. PLoS ONE 2017;12(2):e0171316. [10.1371/journal.pone.0171316]

\section{Hanson 2014}

Hanson C, Waiswa P, Marchant T, Marx M, Manzi F, Mbaruku G, et al. Expanded Quality Management Using Information Power (EQUIP): protocol for a quasiexperimental study to improve maternal and newborn health in Tanzania and Uganda. Implementation Science 2014;9(1):41. [10.1186/1748-5908-9-41]

\section{Harden 2018}

Harden E, Thomas J, Cargo M, Harris J, Pantoja T, Flemming K, et al. Cochrane Qualitative and Implementation Methods Group guidance series - paper 5: methods for integrating qualitative and implementation evidence within intervention effectiveness reviews. Journal of Clinical Epidemiology 2018;97:39-48. DOI: 10.1016/ j.jclinepi.2017.10.023

Higgins 2011

Higgins JPT, Green S, editor(s). Cochrane Handbook for Systematic Reviews of Interventions Version 5.1.0 (updated March 2011). The Cochrane Collaboration, 2011. Available from handbook.cochrane.org.

\section{Hubbard 2007}

Hubbard G, Kidd L, Donaghy E, McDonald C, Kearney N. A review of literature about involving people affected by cancer in research, policy and planning and practice. Patient Education and Counseling 2007;65(1):21-33. DOI: 10.1016/j.pec.2006.02.009

\section{IPFCC 2012} Institute for Patient- and Family-Centered Care. What is PFCC?. www.ipfcc.org/about/pfcc.html (accessed 24 July 2018).

The effects of consumers and health providers working in partnership as an intervention for the promotion of person-centred health 
Jun 2018

Jun GT, Canham A, Altuna-Palacios A, Ward JR, Bhamra $\mathrm{R}$, Rogers $\mathrm{S}$, et al. A participatory systems approach to design for safer integrated medicine management. Ergonomics 2018;61(1):48-68. DOI: 10.1080/ 00140139.2017 .1329939

Kaufman 2011

Kaufman J. Infographics. cccrg.cochrane.org/Infographics (accessed 2 July 2019).

Klein 1999

Klein S, Tracy D, Kitchener HC, Walker LG. The effects of the participation of patients with cancer in teaching communication skills to medical undergraduates: a randomised study with follow-up after 2 years. European Journal of Cancer 1999;35(10):1448-56. DOI: 10.1016/ S0959-8049(99)00153-7

Legaré 2014

Legaré F, Stacey D, Turcotte S, Cossi MJ, Kryworuchko J, Graham ID, et al. Interventions for improving the adoption of shared decision making by healthcare professionals. Cochrane Database of Systematic Reviews 2014, Issue 9. DOI: 10.1002/14651858.CD006732.pub3

Leyshon 2015

Leyshon S, McAdam S. Scene setter: the importance of taking a systems approach to person-centred care. $B M J$ 2015;350:h985. DOI: 10.1136/bmj.h985

\section{Liberati 2009}

Liberati A, Altman DG, Tetzlaff J, Mulrow C, Gøtzsche PC, Ioannidis JP, et al. The PRISMA statement for reporting systematic reviews and meta-analyses of studies that evaluate health care interventions: explanation and elaboration. PLoS Medicine 2009;6:e1000100.

\section{Luxford 2011}

Luxford K, Safran DG, Delbanco T. Promoting patientcentered care: a qualitative study of facilitators and barriers in healthcare organizations with a reputation for improving the patient experience. International Journal for Quality in Health Care 2011;23(5):510-5. DOI: 10.1093/intqhel mzr024

Mackintosh 2017

Mackintosh NJ, Davis RE, Easter A, Rayment-Jones H, Sevdalis N, Wilson S, et al. Interventions to increase patient and family involvement in escalation of care for acute life-threatening illness in community health and hospital settings. Cochrane Database of Systematic Reviews 2017, Issue 10. DOI: 10.1002/14651858.CD012829

\section{McKenzie 2017}

McKenzie E, Potestio ML, Boyd JM, Niven DJ, BrundinMather R, Bagshaw SM, et al. Reconciling patient and provider priorities for improving the care of critically ill patients: a consensus method and qualitative analysis of decision making. Health Expectations 2017;20(6):1367-74. DOI: $10.1111 /$ hex.12576

\section{Merner 2019}

Merner B, Hill S, Colombo C, Xafis V, Gaulden CM, Graham-Wisener L, et al. Consumers and health providers working in partnership for the promotion of personcentred health services: a co-produced qualitative evidence synthesis.. Cochrane Database of Systematic Reviews 2019, Issue 2. DOI: 10.1002/14651858.CD013274

\section{Mockford 2012}

Mockford C, Staniszewska S, Griffiths F, Herron-Marx S. The impact of patient and public involvement on UK NHS health care: a systematic review. International Journal of Qualilty in Health Care 2012;24(1):28-38.

Moore 2017

Moore L, Britten N, Lydahl D, Naldemirci O, Elam M, Wolf A. Barriers and facilitators to the implementation of person-centred care in different healthcare contexts. Scandinavian Journal of Caring Sciences 2017;31(4):662-73. DOI: $10.1111 /$ scs. 12376

\section{Nelson 1998}

Nelson G, Ochocka J, Griffin K, Lord J. 'Nothing about me, without me': participatory action research with selfhelp/mutual aid organizations for psychiatric consumer/ survivors. American Journal of Community Psychology 1998; 26(6):881-912. DOI: 10.1023/A:1022298129812

\section{Nilsen 2006}

Nilsen ES, Myrhaug HT, Johansen M, Oliver S, Oxman AD. Methods of consumer involvement in developing healthcare policy and research, clinical practice guidelines and patient information material. Cochrane Database of Systematic Reviews 2006, Issue 3. DOI: 10.1002/ 14651858.CD004563.pub2

\section{Ocloo 2016}

Ocloo J, Matthews R. From tokenism to empowerment: progressing patient and public involvement in healthcare improvement. BMJ Quality \& Safety 2016;25(8):626-32. DOI: $10.1136 /$ bmjqs-2015-004839

\section{Ocloo 2017}

Ocloo J, Garfield S, Dawson S, Dean Franklin B. Exploring the theory, barriers and enablers for patient and public involvement across health, social care and patient safety: a protocol for a systematic review of reviews. BMJ Open 2018; 7(10):e018426. DOI: 10.1136/bmjopen-2017-018426

\section{Ogden 2017}

Ogden K, Barr J, Greenfield D. Determining requirements for patient-centred care: a participatory concept mapping study. BMC Health Services Research 2017;17(1):780. DOI: 10.1186/s12913-017-2741-y

\section{Ong 2017}

Ong M K, Jones L, Aoki W, Belin TR, Bromley E, Chung $\mathrm{B}$, et al. A community-partnered, participatory, clusterrandomized study of depression care quality improvement: three-year outcomes. Psychiatric Services 2017;68(12): 1262-70. DOI: 10.1176/appi.ps. 201600488

\section{Ottmann 2011}

Ottmann G, Laragy C, Allen J, Feldman P. Coproduction in practice: participatory action research to develop a model of community aged care. Systemic Practice and Action Research 2011;24(5):413-27. DOI: 10.1007/s11213-011-9192-x

The effects of consumers and health providers working in partnership as an intervention for the promotion of person-centred health 


\section{Palmer 2015}

Palmer VJ, Chondros P, Piper D, Callander R, Weavell W, Godbee K, et al. The CORE study protocol: a stepped wedge cluster randomised controlled trial to test a co-design technique to optimise psychosocial recovery outcomes for people affected by mental illness in the community mental health setting. BMJ Open 2015;5(3):e006688. DOI: 10.1136/bmjopen-2014-006688

Palmer 2016

Palmer VJ, Piper D, Richard L, Furler J, Herrman $\mathrm{H}$, Cameron J, et al. Balancing opposing forces - a nested process evaluation study protocol for a stepped wedge designed cluster randomized controlled trial of an experience based codesign intervention: the CORE study. International Journal of Qualitative Methods 2016;15(1): 1609406916672216. DOI: 10.1177/1609406916672216

Pelletier 2011

Pelletier J-F, Lesage A, Delorme A, Macaulay A C, Salsberg J, Valle C, Davidson L. User-led research: a global and person-centered initiative. International Journal of Mental Health Promotion 2011;13(1):4-12. DOI: 10.1080/ 14623730.2011.9715645

\section{Picker Institute 1987}

Picker Institute. Principles of Patient-Centred Care. Bethesda (MD): Picker Institute, 1987.

\section{Rathert 2012}

Rathert C, Wyrwich MD, Boren SA. Patient-centered care and outcomes: a systematic review of the literature. Medical Care Research Reviews 2012;70(4):351-79.

\section{Repper 2007}

Repper J, Breeze J. User and carer involvement in the training and education of health professionals: a review of the literature. International Journal of Nursing Studies 2007; 44(3):511-9. DOI: 10.1016/j.ijnurstu.2006.05.013

Review Manager 2014 [Computer program] Nordic Cochrane Centre, The Cochrane Collaboration. Review Manager 5 (RevMan 5). Version 5.3. Copenhagen: Nordic Cochrane Centre, The Cochrane Collaboration, 2014.

\section{Ryan 2013}

Ryan R, Hill S, Prictor M, McKenzie J, Cochrane Consumers and Communication Group. Study quality guide. cccrg.cochrane.org/author-resources (accessed 24 July 2018).

Ryan 2016

Ryan R, Horey D, Oliver S, McKenzie J, Prictor M, Santesso $\mathrm{N}$, et al. Cochrane Consumers and Communication Group standard protocol text and additional guidance for review authors. cccrg.cochrane.org/author-resources. Melbourne: La Trobe University, (accessed 24 July 2018).

\section{Sanders 2008}

Sanders EBN, Stappers PJ. Co-creation and the new landscapes of design. CoDesign 2008;4(1):5-18. DOI: $10.1080 / 15710880701875068$

\section{Schünemann 2011}

Schünemann HJ, Oxman AD, Higgins JPT, Vist GE, Glasziou P, Guyatt GH. Chapter 11: Presenting results and 'Summary of findings' tables. In: Higgins JPT, Green S, editor(s). Cochrane Handbook for Systematic Reviews of Interventions Version 5.1.0 (updated March 2011). The Cochrane Collaboration, 2011. Available from handbook.cochrane.org.

Sharma 2015

Sharma T, Bamford M, Dodman D. Person-centred care: an overview of reviews. Contemporary Nurse 2015;51(2-3): 107-20. DOI: $10.1080 / 10376178.2016 .1150192$

\section{Shields 2012}

Shields L, Zhou H, Pratt J, Taylor M, Hunter J, Pascoe E. Family-centred care for hospitalised children aged 0 to 12 years. Cochrane Database of Systematic Reviews 2012, Issue 10. DOI: 10.1002/14651858.CD004811.pub3

Stacey 2017

Stacey D, Legaré F, Lewis K, Barry MJ, Bennett CL, Eden $\mathrm{KB}$, et al. Decision aids for people facing health treatment or screening decisions. Cochrane Database of Systematic Reviews 2017, Issue 4. DOI: 10.1002/14651858.CD001431.pub5

\section{Stone 2008}

Stone $\mathrm{S}$. A retrospective evaluation of the impact of the Planetree patient-centered model of care on inpatient quality outcomes. Health Environments Research \& Design 2008;1(4):55-69.

\section{Synnot 2018}

Synnot A, Bragge P, Lowe D, Nunn J, O'Sullivan M, Horvat $\mathrm{L}$, et al. Research priorities in health communication and participation: international survey of consumers and other stakeholders. BMJ Open 2018;8:e019481. DOI: 10.1136/ bmjopen-2017-019481

\section{Synnot 2019}

Synnot A, Tong A, Bragge P, Lowe D, Nunn JS, O'Sullivan $\mathrm{M}$, et al. Selecting, refining and identifying priority Cochrane Reviews in health communication and participation in partnership with consumers and other stakeholders. Health Research Policy and Systems 2019; Vol. 17, issue 1. DOI: 10.1186/s12961-019-0444-z

\section{Tritter 2003}

Tritter J, Barley V, Daykin N, Evans S, McNeill J, Rimmer $\mathrm{J}$, et al. Divided care and the third way: user involvement in statutory and voluntary sector cancer services. Sociology of Health \& Illness 2003;25:429-56. DOI: 10.1111/ $1467-9566.00353$

\section{Waiswa 2016}

Waiswa P, O'Connell T, Bagenda D, Mullachery P, Mpanga F, Henriksson DK, et al. Community and District Empowerment for Scale-up (CODES): a complex districtlevel management intervention to improve child survival in Uganda: study protocol for a randomized controlled trial. Trials 2016;17(1):135. [10.1186/s13063-016-1241-4]

\section{WHO 2009}

World Health Organization (WHO). Building a working definition of a partnership. www.who.int/patientsafety/

The effects of consumers and health providers working in partnership as an intervention for the promotion of person-centred health 
implementation/apps/resources/defining-partnershipsapps.pdf (accessed 24 July 2018).

\section{Wildridge 2004}

Wildridge V, Childs S, Cawthra L, Madge B. How to create successful partnerships - a review of the literature. Health Information and Libraries Journal 2004;21(Suppl 1):3-19. DOI: $10.1111 /$ j.1740-3324.2004.00497.x

\section{Wiles 2018}

Wiles L, Kay D, Synnot A, Luker J, Hillier S. Consumer engagement in health care policy, research and services: methods and effects. www.crd.york.ac.uk/PROSPERO/ display_record.php?ID=CRD42018102595 (accessed 24 July 2018).

\section{Wolf 2017}

Wolf A, Moore L, Lydahl D, Naldemirci O, Elam M, Britten N. The realities of partnership in person-centred care: a qualitative interview study with patients and professionals. BMJ Open 2017;7(7):e016491. DOI: 10.1136/bmjopen-2017-016491

* Indicates the major publication for the study

\section{ADDITIONAL TABLES}

Table 1. Key components of working in partnership versus usual practice

\begin{tabular}{|c|c|c|c|c|c|c|}
\hline \multirow{2}{*}{$\begin{array}{l}\text { Key compo- } \\
\text { nents of work- } \\
\text { ing in partner- } \\
\text { ship } \\
\begin{array}{l}\text { Working in part- } \\
\text { nership as an in- } \\
\text { tervention }\end{array}\end{array}$} & \multicolumn{2}{|c|}{ (1) Partnership participant types } & \multicolumn{3}{|c|}{ (2) Joint formal group format, meets over time } & \multirow{2}{*}{$\begin{array}{l}\text { (3) Decision re- } \\
\text { lates to person- } \\
\text { centeredness of } \\
\text { health service } \\
\text { Joint decisions } \\
\text { about health } \\
\text { service planning, } \\
\text { delivery, or eval- } \\
\text { uation }\end{array}$} \\
\hline & $\begin{array}{l}\text { At least one con- } \\
\text { sumer }\end{array}$ & $\begin{array}{l}\text { At least } \\
\text { one heath service } \\
\text { provider }\end{array}$ & $\begin{array}{l}\text { Opportunity to } \\
\text { influence delib- } \\
\text { eration and deci- } \\
\text { sion-making by } \\
\text { meeting jointly } \\
\text { (e.g. f2f, online, } \\
\text { phone) }\end{array}$ & $\begin{array}{l}\text { Formal group } \\
\text { format } \\
\text { (e.g. board, com- } \\
\text { mittee, council, } \\
\text { steering or work } \\
\text { group) }\end{array}$ & $\begin{array}{l}\text { Meets more than } \\
\text { once } \\
\text { (e.g. time-lim- } \\
\text { ited or ongoing) }\end{array}$ & \\
\hline $\begin{array}{l}\text { Usual practice - } \\
\text { may con- } \\
\text { tain some, but } \\
\text { not all, key com- } \\
\text { ponents of work- } \\
\text { ing in partner- } \\
\text { ship }\end{array}$ & $\begin{array}{l}\text { e.g. no consumer } \\
\text { participant, or } \\
\text { consumer(s) in- } \\
\text { volved, but not } \\
\text { in decision-mak- } \\
\text { ing }\end{array}$ & $\begin{array}{l}\text { (or) } \\
\text { no health service } \\
\text { provider partici- } \\
\text { pant, or provider } \\
\text { (s) involved, but } \\
\text { not in decision- } \\
\text { making }\end{array}$ & $\begin{array}{l}\text { (or) group does } \\
\text { not meet jointly } \\
\text { e.g. independent } \\
\text { deliberation and } \\
\text { decision-making }\end{array}$ & $\begin{array}{l}\text { (or) group is in- } \\
\text { formal or ad-hoc }\end{array}$ & $\begin{array}{l}\text { (or) group meets } \\
\text { only once }\end{array}$ & $\begin{array}{l}\text { (or) } \\
\text { either the con- } \\
\text { sumer or health } \\
\text { service provider } \\
\text { participant pro- } \\
\text { vides feedback, } \\
\text { or acts in an ad- } \\
\text { visory or con- } \\
\text { sultative capac- } \\
\text { ity, rather than } \\
\text { decision-mak- } \\
\text { ing, for health } \\
\text { service planning, } \\
\text { delivery, or eval- } \\
\text { uation }\end{array}$ \\
\hline
\end{tabular}

The effects of consumers and health providers working in partnership as an intervention for the promotion of person-centred health 
Table 2. Data extraction template

\section{Citation}

Name of review author completing this form

Date form completed $\begin{aligned} & \text { Notes (unpublished - for own e.g. references to be followed up, source of information (especially if multiple reports of same trial, or } \\ & \text { use) } \\ & \text { unpublished data or personal communication included) }\end{aligned}$

\begin{tabular}{l|l} 
Notes(published) & $\begin{array}{l}\text { e.g. contact with author (Yes /No), } \\
\text { study translated from a language other than English, (Yes/No) } \\
\text { duplicate publication (Yes/No) } \\
\text { information or unpublished data obtained (Yes/No) }\end{array}$ \\
\hline Notes(published) & e.g. study has qualitative data
\end{tabular}

A. Details of study

Supporting text

Additional notes or queries

\begin{tabular}{|c|c|}
\hline Study design & (RCT, cluster-RCT) \\
\hline Aim of study & $\begin{array}{l}\text { (as stated in the trial report/s. } \\
\text { What was the trial designed to as- } \\
\text { sess?) }\end{array}$ \\
\hline $\begin{array}{l}\text { Aim of intervention } \\
\text { (if different from study aim) }\end{array}$ & $\begin{array}{l}\text { (as stated in the trial report/s. } \\
\text { What was the problem that this } \\
\text { intervention was designed to ad- } \\
\text { dress?) }\end{array}$ \\
\hline $\begin{array}{l}\text { Methods of recruitment of par- } \\
\text { ticipants }\end{array}$ & $\begin{array}{l}\text { (How were potential participants } \\
\text { approached and invited to partic- } \\
\text { ipate?) }\end{array}$ \\
\hline Funding & $\begin{array}{l}\text { (including source, amount, if } \\
\text { stated) }\end{array}$ \\
\hline Sample size/power calculation & $\begin{array}{l}\text { (Was a calculation described, and } \\
\text { were participants recruited to } \\
\text { meet it?) }\end{array}$ \\
\hline Consumer involvement & $\begin{array}{l}\text { (e.g. in design of study, interven- } \\
\text { tion, or both; in delivery of in- } \\
\text { tervention; in evaluation of inter- } \\
\text { vention; in interpretation of study } \\
\text { findings) }\end{array}$ \\
\hline
\end{tabular}

Declaration of interests for the (conflict of interests) primary investigators

The effects of consumers and health providers working in partnership as an intervention for the promotion of person-centred health

Copyright ( 2019 The Cochrane Collaboration. Published by John Wiley \& Sons, Ltd. 
Table 2. Data extraction template (Continued)

\begin{tabular}{|c|c|c|c|}
\hline \multicolumn{2}{|l|}{ B. Location and setting } & \multirow[t]{2}{*}{ Supporting text } & \multirow[t]{2}{*}{ Additional notes or queries } \\
\hline Geographical location & (Statelprovince and country) & & \\
\hline Degree of regional development & (urban/rural) & & \\
\hline Type of healthcare system & $\begin{array}{l}\text { if described } \\
\text { (universal access (taxation or so- } \\
\text { cial insurance), voluntary insur- } \\
\text { ance, individual out-of-pocket, } \\
\text { specified access for low income, } \\
\text { immigrant, or refugee patients) }\end{array}$ & & \\
\hline Context of healthcare system & $\begin{array}{l}\text { (public, government funded or } \\
\text { privately funded services in pri- } \\
\text { mary care, hospital setting, or } \\
\text { community clinics) }\end{array}$ & & \\
\hline C. Participants & & Supporting text & Additional notes or queries \\
\hline
\end{tabular}

Inclusion/exclusion criteria for (providers and consumers) Have participation in study important populations or groups been excluded from the study (e. g. people with more than one concurrent health problem (multimorbidity) or disability, those from any socioeconomic groups)?

\begin{tabular}{|c|c|c|c|}
\hline \multirow[t]{2}{*}{ Number } & \multirow{2}{*}{$\begin{array}{l}\text { (eligible, excluded, refused to take } \\
\text { part, randomised to interven- } \\
\text { tion, randomised to control, ex- } \\
\text { cluded post-randomisation (with } \\
\text { reasons), withdrawn, lost to fol- } \\
\text { low-up, died, included in analy- } \\
\text { sis, included for each outcome) }\end{array}$} & Intervention: & \\
\hline & & Control: & \\
\hline Received intervention & $\begin{array}{l}\text { (proportion of those allocated to } \\
\text { intervention who received it) }\end{array}$ & & \\
\hline Consumer & & Supporting text & Additional notes or queries \\
\hline Categorisation & $\begin{array}{l}\text { (caregiver, consumer, community } \\
\text { member) }\end{array}$ & & \\
\hline Age range & (including standard deviation) & & \\
\hline Gender & $\begin{array}{l}\text { (female only/male only/mixed/ } \\
\text { unclear) }\end{array}$ & & \\
\hline
\end{tabular}

The effects of consumers and health providers working in partnership as an intervention for the promotion of person-centred health 
Table 2. Data extraction template (Continued)

\begin{tabular}{|c|c|c|c|}
\hline Level of education & (if reported) & & \\
\hline Socioeconomic status & (as described by the study) & & \\
\hline Diagnosis & (if reported) & & \\
\hline Other & $\begin{array}{l}\text { (e.g. literacy or reading level; pre- } \\
\text { vious partnership experience) }\end{array}$ & & \\
\hline Provider & & Supporting text & Additional notes or queries \\
\hline Categorisation & (GP; allied health worker, etc) & & \\
\hline Age range & (including standard deviation) & & \\
\hline Gender & $\begin{array}{l}\text { (female only/male only/mixed/ } \\
\text { unclear) }\end{array}$ & & \\
\hline Level of education & (if reported) & & \\
\hline Socioeconomic status & (as described by the study) & & \\
\hline Number of years practicing & (if reported) & & \\
\hline Other & $\begin{array}{l}\text { (e.g. previous partnership experi- } \\
\text { ence) }\end{array}$ & & \\
\hline D. Intervention & & Supporting text & Additional notes or queries \\
\hline $\begin{array}{l}\text { Intervention name } \& \text { number } \\
\text { of groups }\end{array}$ & $\begin{array}{l}\text { (list all for each intervention } \\
\text { group) }\end{array}$ & & \\
\hline Intervention purpose & $\begin{array}{l}\text { (including author's terminology } \\
\text { re: partnering and person cen- } \\
\text { tred-care) }\end{array}$ & & \\
\hline Context of partnering & $\begin{array}{l}\text { (describe formal committee or } \\
\text { group e.g. autonomous, semi-au- } \\
\text { tonomous, government controlled } \\
\text { board or body; governance com- } \\
\text { mittee; community advisory; pa- } \\
\text { tient council; co-design; co-pro- } \\
\text { duction; quality and safety com- } \\
\text { mittee; feedback from, experience } \\
\text { of committee) }\end{array}$ & & \\
\hline
\end{tabular}

The effects of consumers and health providers working in partnership as an intervention for the promotion of person-centred health 
Table 2. Data extraction template (Continued)

Was the partnering tailored, (ifso, describe what was done and modified, adapted? why)

Was training provided to part- (ifso, describe what was done and ners? why)

Format or delivery mode of (face-to-face, online, telephone; meeting note: must be real-time)

Partnership duration (ongoing or time-limited)

Frequency of partnership meet- (must be more than once)

ings

Duration of meetings

(e.g. average, total length of time meeting)

Deliverer

(who was responsible for organ-

ising (researchers; management;

etc); host organisation)

Location of meetings (onsite at health setting; other location)

Type of decision-making activ- (discuss, approve budget; set priity orities; identify problems; design solutions; implement initiatives; develop policies; identify and monitor performance indicators; other?)

Decision-making process, attempts to resolve conflict

(e.g. consensus, vote, agreement, etc.)

Diversity of consumer and provider participants

(e.g. caregivers, vulnerable people, range of health providers)

Ratio of consumers to providers

(e.g. consumer majority; consumer minority; equal)

Attempts to address intrinsic power imbalances

(e.g. provision of salary or financial reimbursement, orientation, training, coaching or support e.g. via an advocate, facilitator, moderator, mentor, or consumer liaison officer) 
Table 2. Data extraction template (Continued)

\begin{tabular}{|c|c|c|c|}
\hline $\begin{array}{l}\text { Theoretical basis for interven- } \\
\text { tion }\end{array}$ & (if described) & & \\
\hline Fidelity, integrity & $\begin{array}{l}\text { (Was the intervention delivered as } \\
\text { intended? record any assessment of } \\
\text { this) }\end{array}$ & & \\
\hline \multicolumn{4}{|l|}{$\begin{array}{l}\text { Details of control, usual, or rou- } \\
\text { tine care }\end{array}$} \\
\hline $\begin{array}{l}\text { Details of co-interventions in } \\
\text { all groups }\end{array}$ & $\begin{array}{l}\text { (co-interventions may be sepa- } \\
\text { rate to the intervention of inter- } \\
\text { est for this review, or they may be } \\
\text { other similar elements in a suite of } \\
\text { interventions having a common } \\
\text { purpose. Record all relevant infor- } \\
\text { mation) }\end{array}$ & & \\
\hline \multicolumn{2}{|l|}{ E. Primary outcomes } & Supporting text & Additional notes or queries \\
\hline $\begin{array}{l}\text { Additional outcomes measured } \\
\text { by study }\end{array}$ & $\begin{array}{l}\text { (List all outcomes measured by the } \\
\text { study, which do not apply to any } \\
\text { of the chosen review primary and } \\
\text { secondary outcomes) }\end{array}$ & & \\
\hline
\end{tabular}

Primary outcome 1 (repeat for each primary outcome)

\begin{tabular}{l} 
Outcome measured (Yes/no) \\
\hline
\end{tabular}

Description of outcome assessment tool

Validity and reliability of outcome measure

Methods of follow-up for non-respondents

Number of outcome assessments

Timing of outcome assessment (including frequency and length of follow-up)

F. Secondary outcomes

Supporting text

Additional notes or queries

Secondary outcome 1 (repeat for each secondary outcome)

Outcome measured (Yes/no)
(n)

Description of outcome assessment tool

The effects of consumers and health providers working in partnership as an intervention for the promotion of person-centred health 
Table 2. Data extraction template (Continued)

Validity and reliability of outcome measure

Methods of follow-up for non-respondents

Number of outcome assessments

Timing of outcome assessment (including frequency and length of follow-up)

\section{G. Study conclusion}

Conclusion drawn by study au- (Where details are not included thors in the published study, or are unclear, we will contact authors)

\section{H. 'Risk of bias' assessment Review authors' judgment}

Judgment and supporting Additional notes or queries text

Random sequence generation

Describe the method used to gen(high risk, low risk, unclear) erate the allocation sequence in sufficient detail to allow an assessment of whether it should produce comparable groups

Allocation concealment (to intervention)
Describe the method used to conceal the allocation sequence in sufficient detail to determine whether intervention allocations could have been foreseen in advance of, or during, enrolment
Blinding of participants and personnel (for each main outcome)
Describe all measures used, if participants any, to blind study participants and personnel from knowledge of which intervention a participant received. Provide any information relating to whether the intended blinding was effective.

Personnel

\section{(high risk, low risk, unclear)} (high risk, low risk, unclear) (high risk, low risk, unclear)
Blinding of outcome assessment

(for each main class of outcome)
Describe all measures used, if (high risk, low risk, unclear) any, to blind outcome assessors from knowledge of which intervention a participant received. Provide any information relating to whether the intended blinding was effective. If the outcome is objective (e.g. length of hospitalstay) the rating should be low risk. 
Table 2. Data extraction template (Continued)

Incomplete outcome data (for each main outcome)
Describe the completeness of outcome data for each main outcome, including attrition and exclusions from the analysis. State whether attrition and exclusions were reported, the numbers in each intervention group (compared with total randomised participants), reasons for attrition and exclusions where reported, and any re-inclusions in analyses performed by the review authors.
Selective reporting

Other sources of bias
State how the possibility of selective outcome reporting was examined by the review authors, and what was found. This is likely to be 'unclear', unless a protocol is provided for the trial. Also report if any outcome is mentioned, but the results are not reported.

(high risk, low risk, unclear)

(high risk, low risk, unclear)

(high risk, low risk, unclear)

examples: contamination; baseline imbalance not explained by previously mentioned categories; blocked randomisation in unblinded trials. Note, this is not a judgment on quality of trial. The main risk of bias concerns for cluster-RCTs are: (i) recruitment bias (differential participant recruitment in clusters for different interventions); (ii) baseline imbalance; (iii) loss of clusters; (iv) incorrect analysis; and ( $v$ ) comparability with individually randomised trials.

(added) Selective recruitment of participants (cluster-RCTs)
Recruitment bias can occur when individuals are recruited to the trial after the clusters have been randomised, as the knowledge of whether each cluster is an intervention' or 'control' cluster could affect the types of participants recruited. (high risk, low risk, unclear) 


\section{A P PENDICES}

\section{Appendix I. Glossary of key terms}

Consumer partnership participant(s): refers to people who are fulfilling an advisory or representative role within the partnership. These roles might include a consumer or patient representative; consumer consultant; consumer with acute or chronic condition(s), their carer, or family member; community members, general public, or citizens; representatives, consultants, or members of consumer organisations.

Facilitated partnership: assistance is provided (e.g. by researchers, consumer advocates, or others) to help partnership participants to work in partnership (e.g. provide training or support before, or moderate or advocate during meetings).

Formal group format: refers to an organised group, such as a committee, council, board, or steering group.

Health services: defined as public or privately funded services that provide direct care to consumers in primary (e.g. community health centres, general practitioner practices, private practices, dispensaries), secondary (e.g. specialist outpatient clinics), or tertiary settings (e.g. hospitals). We will include home and residential services only when they primarily provide health or nursing care (e.g. home-based nursing services, nursing homes, residential rehabilitation services, or hospices).

Health service performance information (as an added intervention): data are collected about the performance of health service beyond that experienced by partnership participants (i.e. could be information about a measure of service quality at baseline, or performance in relation to other services), and provided to partnership participants for consideration during decision-making. Alternatively, consumer and provider partnership participants independently generate health service performance indicator ratings before meeting as a group. Health service user or provider (demand or supply side) information (as an added intervention): data are collected about the needs, preferences, experiences, or priorities of the people who use (demand side), or who provide (supply side) the health service, beyond those who are partnership participants (i.e. additional information is gathered systematically from health service users and providers as part of the trial), and provided to partnership participants for consideration during decision-making.

Intervention effects review: in a systematic review of intervention effects, the researchers aim to locate, assess the risk of bias, and synthesise all of the available evidence related to a specific research question about the effects of an intervention. In this case, the question is 'what are the effects of consumers and providers working in partnership to promote person-centred health services'?

Partnership at health service level (i.e. upstream, at a higher level than the point of care): consumer and health providers jointly plan, develop, and monitor health services at the national, state, or regional policy or organisational governance level.

Parternship at point of care: refers the clinical consultation (or encounter) level during which individual health practitioner(s) interact with individual patient(s) to jointly plan and manage their own health care, sometimes called the direct care level (can include more than one consumer and provider interacting in self-management groups). Partnerships at the point of care level are excluded from this review.

Provider partnership participant(s): refers to people who are fulfilling an advisory or representative role within the partnership. These roles might include, for example: a clinician (such as a doctor, nurse, allied health, or community health worker from any discipline), health service manager, supervisor, or administrator (including quality co-ordinators, chief executives, etc.), health policy maker, or consumer liaison officer. Health provider participants do not include people who are primarily health researchers or academics.

Qualitative evidence synthesis: in a systematic review of qualitative evidence, the researchers aim to locate, assess the methodological quality, and synthesise evidence related to a specific research question about the experience of a phenomenon. When combined with an intervention effects review, the qualitative evidence synthesis aims to help understand how the intervention works, for whom, and in what context, and how best to implement it (Flemming 2019). In this case, the question is 'what are the barriers, facilitators, and experiences of consumers and providers working in partnership to promote person-centred health services'?

Working in partnership (as an intervention): defined as a joint meeting of at least one consumer and health provider, which occurs more than once, in a formal group format, to make decisions together, with the aim of promoting person-centred care in one or more areas of a health service or services. The group is to meet face-to-face or virtually (i.e. meet in real-time, on an ongoing or time-limited basis).

The effects of consumers and health providers working in partnership as an intervention for the promotion of person-centred health 


\section{Appendix 2. MEDLINE search strategy}

1. exp Community Participation/

2. Stakeholder Participation/

3. Decision Making/

4. exp Patient-Centered Care/

5. ((patient* or communit $^{*}$ or consumer* or user* or carer* ${ }^{*}$ or caregiver* ${ }^{*}$ or client* or famil* or lay*) adj3 (decid* or decision* ${ }^{*}$ engag* or involv* or participat*)).ti,ab,kf.

6. or/1-5

7. "Health Priorities"/

8. exp Patient Care Team/

9. exp Ambulatory Care Facilities/

10. *"Mental Health Services"/

11. *"Community Health Services"/

12. *"Health Services Administration"/

13. "Quality Improvement"/

14. *"Hospitals, Public"/

15. "Quality of Health Care"/

16. "Delivery of Health Care"/

17. "Delivery of Health Care, Integrated"/

18. or/7-17

19. "Community-Institutional Relations"/

20. "Advisory Committees"/og

21. (partner* or participat* or consult* or decision* or deliberation* or co\#design* or involv* or contribut* or role* or empower* or engag* or collab* or advoca* or organi\#ation* or respons*).ti,ab,kf.

22. (experience based adj2 design).ti,ab,kf.

23. or/19-22

24. randomized controlled trial.pt.

25. controlled clinical trial.pt.

26. randomized.ab.

27. placebo.ab.

28. drug therapy.fs.

29. randomly.ab.

30. trial.ab.

31. groups.ab.

32. or $/ 24-31$

33. Non-Randomized Controlled Trials as Topic/

34. ((cluster or quasi) adj3 trial*).tw.

35. or/33-34

36. exp animals/ not humans.sh.

37. 32 not 36

38. 35 not 36

39. limit 37 to (english language and $\mathrm{yr}=" 2000$-Current")

40. limit 38 to (english language and $y r=" 2000$-Current")

41. and $/ 6,18,23,39$

42. and $/ 6,18,23,40$

43. or $/ 41-42$

The effects of consumers and health providers working in partnership as an intervention for the promotion of person-centred health 


\section{CONTRIBUTIONSOFAUTHORS}

DL: conceptual development of the protocol, drafting of the protocol, organising and participating in the Stakeholder Panel workshop SH: conceptual development of the protocol, drafting of the protocol, organising and participating in Stakeholder Panel meetings and the workshop

BM: conceptual development of the protocol, providing feedback on drafts, organising and participating in Stakeholder Panel meetings and the workshop

LW: conceptual development of the protocol, providing feedback on drafts, organising and participating in the Stakeholder Panel workshop

LGW: conceptual development of the protocol, providing feedback on drafts

\section{DECLARATIONSOF INTEREST}

DL is the Technical Editor for the Cochrane Consumers and Communication Group.

$\mathrm{SH}$ is the Joint Co-ordinating Editor of the Cochrane Consumers and Communication Group.

$\mathrm{BM}$ is the Managing Editor of the Cochrane Consumers and Communication Group.

LW is the Assistant Managing Editor of the Cochrane Consumers and Communication Group.

LGW: none known.

The work of the Cochrane Group is situated within the Centre for Health Communication and Participation, La Trobe University, and is supported, in part, by grants from Safer Care Victoria and the National Health and Medical Research Centre. SH, BM, DL and $\mathrm{LW}$ were not involved in the editorial processes for this protocol.

\section{SOURCES OF SUPPORT}

\section{Internal sources}

- La Trobe University, Australia.

BM receives funding from La Trobe University to undertake this review.

\section{External sources}

- Safer Care Victoria and the National Health and Medical Research Centre, Australia.

The work of the Cochrane Group is situated within the Centre for Health Communication and Participation, La Trobe University, and is supported, in part, by grants from Safer Care Victoria and the National Health and Medical Research Centre. 


\section{NOTES}

This protocol is based on standard text and guidance provided by Cochrane Consumers and Communication (Ryan 2016).

The effects of consumers and health providers working in partnership as an intervention for the promotion of person-centred health 